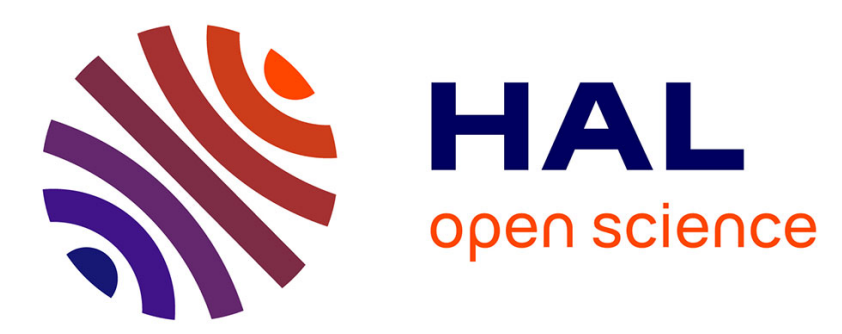

\title{
A 3D physical model to study the behavior of vegetation fires at laboratory scale
}

Dominique Morvan, Gilbert Accary, Sofiane Meradji, Nicolas Frangieh, Oleg Bessonov

\section{- To cite this version:}

Dominique Morvan, Gilbert Accary, Sofiane Meradji, Nicolas Frangieh, Oleg Bessonov. A 3D physical model to study the behavior of vegetation fires at laboratory scale. Fire Safety Journal, 2018, 101, pp.39-52. 10.1016/j.firesaf.2018.08.011 . hal-02114685

\section{HAL Id: hal-02114685 \\ https://hal-amu.archives-ouvertes.fr/hal-02114685}

Submitted on 29 Apr 2019

HAL is a multi-disciplinary open access archive for the deposit and dissemination of scientific research documents, whether they are published or not. The documents may come from teaching and research institutions in France or abroad, or from public or private research centers.
L'archive ouverte pluridisciplinaire HAL, est destinée au dépôt et à la diffusion de documents scientifiques de niveau recherche, publiés ou non, émanant des établissements d'enseignement et de recherche français ou étrangers, des laboratoires publics ou privés. 


\section{Accepted Manuscript}

A 3D physical model to study the behavior of vegetation fires at laboratory scale

Dominique Morvan, Gilbert Accary, Sofiane Meradji, Nicolas Frangieh, Oleg

Bessonov

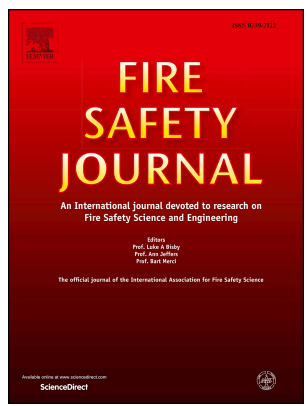

PII:

S0379-7112(18)30022-5

DOI:

10.1016/j.firesaf.2018.08.011

Reference: FISJ 2739

To appear in: Fire Safety Journal

Received Date: 16 January 2018

Revised Date: 13 August 2018

Accepted Date: 16 August 2018

Please cite this article as: D. Morvan, G. Accary, S. Meradji, N. Frangieh, O. Bessonov, A 3D physical model to study the behavior of vegetation fires at laboratory scale, Fire Safety Journal (2018), doi: 10.1016/j.firesaf.2018.08.011.

This is a PDF file of an unedited manuscript that has been accepted for publication. As a service to our customers we are providing this early version of the manuscript. The manuscript will undergo copyediting, typesetting, and review of the resulting proof before it is published in its final form. Please note that during the production process errors may be discovered which could affect the content, and all legal disclaimers that apply to the journal pertain. 


\title{
A 3D physical model to study the behavior of vegetation fires at laboratory scale
}

\author{
Dominique Morvan ${ }^{1 *}$, Gilbert Accary ${ }^{2}$, Sofiane Meradji ${ }^{3}$, Nicolas Frangieh ${ }^{1}$, Oleg Bessonov ${ }^{4}$ \\ ${ }^{1}$ Aix-Marseille University, CNRS, Centrale Marseille, M2P2, Marseille, France \\ ${ }_{2}^{2}$ Scientific Research Center in Engineering, Lebanese University, Lebanon \\ 3 IMATH, EA 2134, Toulon University, France \\ ${ }^{4}$ Institute for Problems in Mechanics RAS, Russia
}

(*) Corresponding author: dominique.morvan@univ-amu.fr

\begin{abstract}
A 3D multi-physical model referred to as "FireStar3D" has been developed in order to predict the behavior of wildfires at a local scale $(<500 \mathrm{~m})$. In the continuity of a previous work limited to $2 \mathrm{D}$ configurations, this model consists of solving the conservation equations of the coupled system composed of the vegetation and the surrounding gaseous medium. In particular, the model is able to account explicitly for all the mechanisms of degradation of the vegetation (by drying, pyrolysis, and heterogeneous combustion) and the various interactions between the gas mixture (ambient air + pyrolysis and combustion products) and the vegetation cover such as drag force, heat transfer by convection and radiation, and mass transfer. Compared to previous work, some new features were introduced in the modelling of the surface combustion of charcoal, the calculation of the heat transfer coefficient between the solid fuel particles and the surrounding atmosphere, and many improvements were brought to the numerical method to enable affordable 3D simulations. The partial validation of the model was based on some comparisons with experimental data collected at small scale fires carried out in the Missoula Fire Sciences Lab's wind tunnel, through various solid-fuel layers and in well controlled conditions. A relative good agreement was obtained for most of the simulations that were conducted. A parametric study of the dependence of the rate of spread on the wind speed and on the fuelbed characteristics is presented.
\end{abstract}

Keywords: Forest fuel fire, Detailed physical fire model, Fire physics

\section{Nomenclature}

$\bar{\phi}, \tilde{\phi}, \phi^{\prime}$

$C_{D}$

$C_{S}$
Reynolds average, Favre average, and fluctuation of a generic field variable $\phi$

Drag coefficient of solid particles

Heat capacity of solid particles 
$38 \quad D$

$39 \quad F_{D i}$

$40 \quad f_{v}$

$41 \quad g_{i}$

$42 h, h_{\alpha}$

$43 h_{S}$

44

45

46

47

48

49

50

51

52

53

54

55
Diameter of cylindrical solid particles

Drag force in direction $i$ resulting from solid particles

Volume fraction of soot in the gas mixture

Gravity acceleration in direction $i$

Enthalpy of the gas mixture and enthalpy of chemical species $\alpha$

Heat transfer coefficient between the gas mixture and the solid particles

$\Delta h_{\text {Char, }} \Delta h_{P y r}, \Delta h_{\text {Vap, }}$

Charcoal combustion heat, pyrolysis heat, and water vaporization heat

Radiation intensity

Total irradiance

Turbulent kinetic energy

Nusselt number of solid particles

Superscript referring to a vegetation family

Vegetation moisture content

Mass rate of production of chemical species $\alpha$ resulting from vegetation decomposition

Pressure of the gas mixture and partial pressure of chemical species $\alpha$ in the mixture

Thermodynamic and hydrostatic pressures of the gas mixture

Laminar and turbulent Prandtl numbers of the gas mixture

Rate of heat transferred to the solid particles (total, from solid-fuel combustion, and by convection)

Universal ideal gas constant and specific gas constant of chemical species $\alpha$

Rayleigh number of cylindrical solid particles

Reynolds number of cylindrical solid particles

Turbulent Reynolds number

Rate of spread of fire

Schmidt number of chemical species

Time

Temperature of the gas mixture and of the solid particles

Wind speed at wind tunnel entrance

Velocity vector component in direction $i$

Cartesian coordinate in direction $i$

Mass fraction of chemical specie $\alpha$ in the gas mixture

Mass fraction of ash, charcoal, dry material, and water in solid particles

\section{Greek symbol}


$\alpha_{G}, \alpha_{S}$

$\alpha_{S G}$

$\delta$

$\delta_{i j}$

$\varepsilon$

$\varphi$

\section{$\lambda$}

$\mu, \mu_{T}, \mu_{e}$

$v_{\text {Char, }} v_{\text {Soot }}, v_{\text {CO2 }}, v_{\text {Ash }}$

$v_{O 2}^{S}, v_{O 2}^{G}, v_{O 2}^{S o o t}$

$\dot{\omega}_{\text {Char }}, \dot{\omega}_{\text {Pyr }}, \dot{\omega}_{\text {Vap }}$

$\dot{\omega}_{\alpha}$

$\rho, \rho_{\text {Dry }}, \rho_{S,}, \rho_{\text {Soot }}, \rho_{S}^{e}$

$\sigma$

$\sigma_{S}$

$\sigma_{G}$

$\tau_{o p t}$

Volume fraction of the gaseous phase and of the solid phase

Fraction of combustion heat absorbed by solid particles

Fuel bed depth

Kronecker coefficient

Dissipation of turbulent kinetic energy

Multiplying factor of $v_{O 2}^{S}$ depending on the molar ratio of $\mathrm{CO}$ to $\mathrm{CO}_{2}$ gases produced from charcoal combustion

Thermal conductivity of the gas mixture

Dynamic viscosity, turbulent viscosity, and effective viscosity of the gas mixture

Mass fraction of charcoal, soot, $\mathrm{CO}_{2}$ gas, and ash resulting from the pyrolysis of dry material

Mass stoichiometric coefficient of charcoal, $\mathrm{CO}$, and soot combustion

Rate of charcoal combustion, of dry material pyrolysis, and of water vaporization in solid particles

Rate of production of chemical species $\alpha$ resulting from reaction in the gaseous phase

Density of the gaseous phase, of dry material, of the solid phase, of soot, and of solid-fuel elements

Stephan-Boltzmann constant

Surface area-to-volume ratio of the solid particles

Absorption coefficient of the gas/soot mixture

Fuel-bed optical thickness

\section{Introduction}

In a near future, numerous factors such as global warming, extensive urbanization, and reduction of agriculture activities could potentially contribute to increase fire hazard in many regions worldwide [1]. However, in adopting the fire ecology point of view [2], wildfires cannot always be considered as a natural disaster, in many cases they contribute to maintain the ecological equilibrium of an ecosystem and help the renewal of forests (in eliminating old trees and promoting, after the fire, the growth of new young trees). The relationship between fires and ecosystems can be summarized by the fire regime, which integrates various characteristics of fire and is generally summarized as the observed average frequency between two fires. A modification of the fire regime, especially if it appears in a short time, is an indication of a perturbation in the life of an ecosystem due to human activities and an evolution of the climate. In this context, if a fire is ignited in a wild ecosystem, the better response could be to do nothing, considering that the perturbation induced by this fire is necessary to maintain a certain equilibrium. However, this approach 
reaches its own limits if the fire affects urban structures such as housing developments in what is commonly referred as the Wildland-Urban Interface (WUI) [3]. The reduction of this natural hazard needs a better understanding of the physical mechanisms governing the behavior of a fire during different phases (ignition, propagation, and extinction), the role played by various parameters characterizing the structure and the state of the vegetation, but also the effects of external conditions such as the wind, air temperature and humidity, the topography, and many other factors. The development of new fire safety engineering tools, based on numerical simulations will allow, in the near future, for the ability to predict the trajectory of a fire front through a landscape (at large scale) or to describe in more details the interaction at a smaller scale between the flames and potential targets located inside the WUI ( e.g., vegetation, houses, etc.) [4,5].

As highlighted in the literature, most of the operational tools developed in order to predict the propagation of a fire front at a landscape scale are based on statistical or semiempirical approaches [6]. Unfortunately, the use of this class of models under conditions that deviate from those used to construct the database, can lead to unacceptable failures; for example, in some cases, the rate of spread of the fire can exceed the wind speed (wind speed measured at a sufficient height $10 \mathrm{~m}$ open wind speed), which is totally unphysical except if the wind speed tends to zero. This has motivated the development of a new class of models, based on a "fully" physical approach, for which the rate of fire spread, and more generally, all variables (flame geometry, fire intensity, etc.) characterizing fire behavior are addressed through the resolution of balance equations governing the various interactions occurring between the vegetation, the surrounding atmosphere, and the flame [5]. The multiphase approach, initially introduced by A.M. Grishin in a monograph at the end of 90's [7], is based on a very detailed modeling of the physicochemical phenomena involved in a fire, from the thermal degradation of the vegetation to the development of the turbulent flame inside and above the vegetation layer. The model developed in this work, referred to as "FireStar3D", can be considered to belong to this multiphase class of models. Globally, this approach solves two sets of problems, one for the vegetation and one for the surrounding gas. These two sets of problems are coupled through additional terms in the balance equations (mass, momentum, and energy) governing the physical system. No modeling of the interface between the solid phase and the gaseous one was introduced in the model, the geometrical complexity (fractal in nature) does not permit an easy description of this interface. In an approach similar to that used to describe fluid flow in a porous medium, the equations were averaged in a representative elementary volume including the two phases. This preliminary operation is responsible for the introduction of additional source terms in the average balance equations (gas production due to pyrolysis, drag force, convection and radiation heat exchange with the solid phase). Except for some particular cases clearly indicated in the text, all the constants of the different sub-models have been fixed from experimental data referenced in Grishin's monograph [7]. Of course, 
the value of these constants are the same for all the reported simulations. Because this kind of model includes a high level of details in representing a propagating fire front and its use is limited to describe the behavior of a fire at a relatively local scale (few hundred meters), which is compatible with the study of the interaction between a wildfire and a house or a building. A very close version of this model is already operational in a $2 \mathrm{D}$ approximation [8-10] , in this case, the problem is solved in a vertical plane defined by the direction of propagation of fire. The 3D extension of the existing model enables to render the 3D effects observed in real fires [11] and to represent the real heterogeneous structure of the vegetation both near the surface (for the shrubs) and the canopy (trees). The main difference between 2D and 3D simulations is that in 2D the fire front is assumed to form a homogeneous obstacle forcing the inlet wind flow to be deviated vertically with the convective plume. In 3D, the heterogeneity of the fire front, forming a succession of peaks and valleys, oscillating under the action of a thermo-convective instability, allows the inlet wind flow to cross the fire front. This difference of behavior of the fire front, contributes to modification of the trajectory of the flame, and also of the plume, and consequently, it greatly affects the interaction between the fire front and the vegetation layer. The difference in behavior between 2D and 3D simulated fires have been investigated by Linn et al. [11] using the coupled atmosphere-fire model HIGRAD/FIRETEC. Even in simulating a quasi-infinite fire front in 3D, using cyclic conditions in the horizontal direction perpendicular to the direction of propagation, the numerical results have highlighted how 3D effects can affect the propagation of the fire, and particularly the relationship rate of spread versus wind speed.

The present paper has two main objectives: (i) to present some details of the 3D model and (ii) to evaluate the potential of the model in predicting the rate of fire spread in wellcontrolled experimental conditions such as the surface fire performed in the wind-tunnel of the Missoula Fire Sciences Lab [12]. One of the main interests in considering the experiments carried out at Missoula Laboratory was that they had been conducted with a significant number of varieties of fuel particles (pines needles, excelsior, sticks) covering a large range of the solid fuel parameters, such as the surface area to volume ratio, the packing ratio, and the moisture content. Before tackling the problem at large scale, for example, simulating grassland fire experiments carried out in Australia or in US [13,14], this paper represents a first step in evaluating the numerical results obtained with our 3D model to experimental laboratory-scale data collected under well-controlled conditions.

\section{Mathematical Model}

The mathematical model of FireStar3D consists of two main parts, coupled through interaction terms. The first part is devoted to the evolution of the state of the vegetation subjected to the intense heat flux coming from the flaming zone. The second part is devoted 
to the calculation of the turbulent-reactive gas flow resulting from the mixture of the pyrolysis and combustion products with the ambient air.

Firestar3D includes most of the characteristics already integrated in the previous 2D version, i.e. a volume decomposition model to represent the different steps of degradation of the vegetation (drying, pyrolysis, char oxidation), a non-equilibrium multiphase model to represent all the fine fuel elements constituting a vegetation layer (foliage, twigs of various diameters), a low Mach number implicit Navier-Stokes solver including a turbulent combustion model in the gaseous phase, and a multiphase model to represent the radiation heat transfer coming both from the gas species $\left(\mathrm{H}_{2} \mathrm{O}, \mathrm{CO}, \mathrm{CO}_{2} \ldots\right)$ and the soot [8-10]. Particular attention was focused on the quality of the numerical convection scheme used for the resolution of the transport equations in the gaseous phase, in order to avoid numerical diffusion (this is capital for turbulence modeling), as well as to the parallelization of the code in order to enable affordable 3D simulations. These characteristics, which can contribute to the future potential of this tool, cannot all be found in the other 3D wildfire models available in the community, such as FIRETEC and WFDS [15-17]. Many of these well-known tools $[16,17]$ use an explicit solver for the resolution of the Navier-Stokes equations; such solvers are usually used to simulate fully compressible flows, which is not the best approach for the simulation of low Mach number flows, mainly because of a wide disparity between the time scales associated with convection and the propagation of acoustic waves [18]. To guarantee the stability of the numerical schemes in the case of fully compressible solvers, the time step and the mesh size must verify CourantFriedrich stability criterion based on the maximum value between the speed of sound and the gas flow velocity. Under the low Mach number approximation, the same criterion is only based on the gas flow velocity. For low Mach number flows, this constitutes a great difference (if one is not interested in the propagation of acoustic waves) since the time step can be easily multiplied by a factor ranged between 10 and 100 (depending the robustness of the convection scheme) without any loss of accuracy in the description of the phenomena of interest. In summary, choosing a fully compressible formulation and an associated explicit solver, as in FIRETEC for example, constitutes a major limitation especially to simulate wildfire at large scale. This is the main reason behind the mesh size used in FIRETEC that can reach, for example, one meter high at ground level, exceeding sometimes the height of the fuel layer, with the consequence that the pyrolysis process and the heat release due to the combustion within the entire fuel layer thickness take place inside one and the same computational cell. In addition, other physical aspects (turbulent combustion, radiation heat transfer, soot production and transport ...) are not well described in WFDS and FIRETEC, especially within the fuel layer. An overview of the discrepancies between these different "fully" physical fire-models can be found in reference [15], summarized also in Tab. 1. 
As indicated in the introduction, some new features have been added in FireStar3D, such as the process of charcoal combustion and the evaluation of the heat transfer coefficient between the solid phase and the gaseous one. These new features are presented in the following parts.

\begin{tabular}{l|ccccc}
\multicolumn{1}{l}{} & FireStar2D & FireStar3D & WFDS & FIRETECH & FIREFOAM \\
\hline Solver & 2D-Implicit & 3D-Implicit & 3D-Explicit & 3D-Explicit & 3D-Implicit \\
Low Mach model & Yes & Yes & Yes & No & Yes $^{(1)}$ \\
Turbulence & TRANS & TRANS/LES & LES & LES & LES \\
TRI model & Yes & No & Yes $^{(2)}$ & Yes & \\
Combustion model & Yes & Yes & Yes & No(3) & No \\
Multi-fuel model & Yes & Yes & Yes & Yes & No \\
Small scale & Yes & Yes & Yes & No & Yes \\
Large scale & Yes $^{(4)}$ & Yes & Yes & Yes & Yes \\
\hline
\end{tabular}

Tab. 1. Summary of main characteristics of four fully physical fire models. (1) Work in progress. (2) The radiation heat transfer was increased empirically. (3) Pyrolysis and combustion take place at the same location without transport into the gaseous phase. (4) With the limitation introduced by the 2D assumption.

\subsection{Solid-Fuel Model}

The heterogeneous character of the vegetation accounted for using two possible shapefamilies of solid fuel particles: cylindrical particles (used to represent branches, twigs, and needles), and disks (used to represent flat leaves). At all steps of the decomposition process, each solid fuel family $m$ is characterized using a set of physical variables: the volume fraction $\left(\alpha_{S}\right)$, the dry material density $\left(\rho_{D r y}\right)$, the moisture content $(M)$, the surface area-to-volume ratio $\left(\sigma_{S}\right)$, the temperature $\left(T_{S}\right)$, and the evolution of the composition of fuel particles in terms of mass fraction of char, water and dry fuel. Measurements of the fire residence time measured for homogeneous solid-fuel beds in laboratory [19], have shown that only small fuel particles $\left(\sigma_{S}>600 \mathrm{~m}^{-1}\right.$ corresponding to a diameter $D<6 \mathrm{~mm}$ for cylindrical shape particles) can contribute actively to the dynamics of a fire. This result was confirmed by wildfire observations, showing that about $90 \%$ of thin fuel particles $(D<6$ $\mathrm{mm}$ ) were consumed in the flaming zone [20]. This threshold represents also the limit separating the thermally thick and thermally thin particles, which means that the temperature gradient inside each solid fuel particles can be neglected in a first approximation. Thermal analysis of forest fuel samples has highlighted that this kind of material were composed of a mixing of lignin, cellulose, hemicellulose, and extractives [21]. 
The composition between these various chemical compounds varies from one species to another and between different parts of a plant (bark, branch, twigs, and foliage). At relatively small heating rate (such as the conditions used in thermogravimetric analysis), the chemical composition of fuel particles can affect the dynamics of thermal decomposition, but at higher heating rate (such as the intense heat flux coming from the flaming zone) the result are less sensitive to chemical composition [21] and seems to be more affected by other parameters such as the surface area-to-volume ratio and the fuel moisture content [22, 24]. For these reasons, we consider: (i) that the decomposition of each vegetation family (regardless its composition) can be summarized in three main steps: dehydration, pyrolysis (in only one step), and surface oxidation, (ii) that each family consists locally of a mixture of water, dry material (cellulose, hemicellulose, and lignin), char, and ash (mineral residue). These components are represented by their mass fractions: $Y_{H 2 O}, Y_{D r y}, Y_{C h a r}$, and $Y_{\text {Ash }}$ respectively, resulting in a local density $\rho_{S}$ of the solidfuel.

The solid-fuel model consists of decomposing the fuelbed zone into homogeneous solidfuel element of effective density $\rho_{S}^{e}=\alpha_{S} \rho_{S}$. It is assumed that the pyrolysis process would be activated only if the dehydration was entirely completed, and that surface oxidation would begin only if the pyrolysis process came to an end.

In the dehydration phase, the evapotranspiration process is reduced to a simple vaporization, during which the temperature of the solid fuel element $T_{S}$ is assumed to remain constant at $373 \mathrm{~K}$. The rate of heat transfer $\dot{Q}_{S}$ received by that fuel element from the flaming zone only serves to produce water vapor at the mass rate:

$$
\dot{\omega}_{V a p}=\dot{M}_{H 2 O}=\dot{Q}_{S} / \Delta h_{V a p}
$$

where $\Delta h_{V a p}=2.25 \times 10^{3} \mathrm{~kJ} / \mathrm{kg}$ is the heat of vaporization.

The decomposition of dry combustible by pyrolysis produces gaseous products (CO and $\mathrm{CO}_{2}$ ) and charcoal. The decomposition of $1 \mathrm{~kg}$ of dry combustible is assumed to produce $v_{\text {Char }}=0.338 \mathrm{~kg}$ of carbon $(0.288 \mathrm{~kg}$ of charcoal and $0.05 \mathrm{~kg}$ of soot $), v_{\mathrm{CO} 2}=0.2 \mathrm{~kg}$ of $\mathrm{CO}_{2}$ and $1-v_{\text {Char }}-v_{C O 2}=0.462 \mathrm{~kg}$ of CO. By contact with the oxygen contained in the ambient air, the hot combustible pyrolysis-products ( $\mathrm{CO}$ and soot) ignite homogeneously in the gaseous phase. Taking into account these assumptions, the pyrolysis process obeys to the following transformation equation written for $1 \mathrm{~kg}$ of dry combustible:

$$
\text { Dry combustibe } \rightarrow\left(v_{\text {Char }}-v_{\text {Soot }}\right) \text { Char }+v_{\text {Soot }} \text { Soot }+v_{\mathrm{CO}_{2}} \mathrm{CO}_{2}+\left(1-v_{\text {Char }}-v_{\mathrm{CO} 2}\right) \mathrm{CO}
$$

The pyrolysis process is assumed to take place when the solid fuel element $T_{S}$ is between $400 \mathrm{~K}$ and $500 \mathrm{~K}[8,19,21]$ at the mass rate: 


$$
\dot{\omega}_{P y r}=\frac{\dot{Q}_{S}}{\Delta h_{P y r}} \times \frac{T_{S}-400}{500-400}
$$

291

292

293

294

295

296

297

298

299

300

301

302

303

304

305

306

307

308

309

310

311

312

313

314

315

316

317

318

319

320

321

where $\Delta h_{P y r}$ is the pyrolysis heat that depend on the vegetation species. We can notice that this range of temperature values is slightly lower than the range 473-573 $\mathrm{K}$ found in [21]. This discrepancy can be explained by a scale effect: in the present study, the solid-fuel temperature represents an average value evaluated within a $1 \mathrm{~cm}^{3}$ volume (with a temperature gradient reported in [21]), whereas the temperature reported in [21] was measured with a $0.5 \mathrm{~mm}$ thermocouple. In addition, this temperature range [400-500 K] has allowed us to obtain the best results in comparison with experimental data obtained at the same scale and comparable solid fuel [25] (see also Fig. 1 in reference [8]). Thus according to Eq. 3, a portion of the rate of heat transfer $\dot{Q}_{S}$ received by the fuel element contributes to the pyrolysis process, while the remaining portion of $\dot{Q}_{S}$ continues to increase the solid fuel temperature $T_{S}$. Note that $T_{S}$ cannot exceed $500 \mathrm{~K}$ as long as the pyrolysis process has not ended.

Unlike previous works [8-10] that arbitrary assumed a complete combustion of charcoal (thus producing only $\mathrm{CO}_{2}$ ) at the solid-fuel particles, in the present work the model representing the surface oxidation of charcoal has been modified to account for a possible incomplete combustion, thus producing both $\mathrm{CO}$ and $\mathrm{CO}_{2}$. According to [23], the balance equation written for $1 \mathrm{~kg}$ of charcoal is given by:

$$
C+v_{O 2}^{S} \varphi O_{2} \rightarrow\left(2+v_{O 2}^{S}\right)(1-\varphi) C O+\left(1+v_{O 2}^{S}\right)(2 \varphi-1) C O_{2}
$$

where $v_{O 2}^{S}=8 / 3$ and $v_{O 2}^{S} \varphi$ is the mass stoichiometric coefficient, it depends on the molar ratio of $\mathrm{CO}$ to $\mathrm{CO}_{2}$ gases produced from charcoal combustion and is given by:

$$
\varphi=\frac{2+\mathrm{CO} / \mathrm{CO}_{2}}{2 \times \mathrm{CO} / \mathrm{CO}_{2}+2}
$$

The molar ratio of $\mathrm{CO}$ to $\mathrm{CO}_{2}$ gases depends on the surface temperature $T_{S}$ according to the following relation [23]:

$$
\mathrm{CO} / \mathrm{CO}_{2}=2500 \exp \left(-6240 / T_{S}\right)
$$

At low temperatures, $\varphi \rightarrow 1$ and only $\mathrm{CO}_{2}$ is produced, while at high temperatures, $\varphi \rightarrow 0.5$ and only CO is practically produced.

The reaction rate of charcoal combustion is approximated by the following Arrhenius law:

$$
\dot{\omega}_{\text {Char }}=k_{\text {Char }} P_{O 2} \exp \left(-E_{\text {Char }} / R_{0} T_{S}\right) \alpha_{S} \sigma_{S}
$$

where $P_{02}$ is the partial pressure of $\mathrm{O}_{2}$ at the solid fuel particle surface. The frequency factors $k_{\text {Char }}=254.2 \mathrm{~kg} /\left(\mathrm{m}^{2} . \mathrm{s} . \mathrm{atm}\right)$ and activation energy $E_{\text {Char }} / R_{0}=9000 \mathrm{~K}$ are evaluated experimentally from a thermal analysis [23]. 
Heat released during charcoal combustion, taking place at the surface of a solid-fuel particle, is assumed to be absorbed both by the solid-fuel element and by the gaseous phase. The rate of heat absorbed by the solid-fuel element is calculated as follows:

$$
\dot{Q}_{S, \text { Char }}=\alpha_{S G} \Delta h_{\text {Char }} \dot{\omega}_{\text {Char }}
$$

where $\Delta h_{\text {Char }}$ is the combustion heat given by:

$$
\Delta h_{\text {Char }}=\left(2+v_{O 2}^{S}\right)(1-\varphi) \Delta h_{C O}+\left(1+v_{O 2}^{S}\right)(2 \varphi-1) \Delta h_{C O 2}
$$

with $\Delta h_{C O}=9 \mathrm{MJ} / \mathrm{kg}$ and $\Delta h_{C O 2}=30 \mathrm{MJ} / \mathrm{kg}$ are the reaction heats of incomplete and complete combustion of carbon that can be obtained from Eq. (2) by setting $\varphi$ at 0.5 and 1 respectively. We assume in this study that heat released during charcoal combustion is equally shared by the gaseous phase and by the solid-fuel element, i.e. $\alpha_{S G}=0.5$.

Taking into account all the previous equations and assumptions, time evolution of the composition and the temperature of a family $m$ of solid-fuel particles in the fuelbed are controlled by the following set of six equations [8-10]:

$$
\frac{d}{d t}\left(\alpha_{S}^{m} \rho_{S}^{m} Y_{H 2 O}^{m}\right)=-\dot{\omega}_{V a p}
$$

$$
\frac{d}{d t}\left(\alpha_{S}^{m} \rho_{S}^{m} Y_{D r y}^{m}\right)=-\dot{\omega}_{P y r}
$$

$$
\frac{d}{d t}\left(\alpha_{S}^{m} \rho_{S}^{m} Y_{\text {Char }}^{m}\right)=\left(v_{\text {Char }}-v_{\text {Soot }}\right) \dot{\omega}_{\text {Pyr }}-\left(1+\frac{v_{\text {Ash }}}{v_{\text {Char }}}\right) \dot{\omega}_{\text {Char }}
$$

$$
\frac{d}{d t}\left(\alpha_{S}^{m} \rho_{S}^{m}\right)=-\dot{\omega}_{V a p}-\left(1-v_{C h a r}+v_{S o o t}\right) \dot{\omega}_{P y r}-\dot{\omega}_{C h a r}
$$

$$
\frac{d}{d t}\left(\alpha_{S}^{m}\right)=-\frac{1}{\rho_{S}^{m}} \dot{\omega}_{\text {Char }}
$$

$$
\alpha_{S}^{m} \rho_{S}^{m} C_{S}^{m} \frac{d T_{S}^{m}}{d t}=\dot{Q}_{S}^{m}-\dot{\omega}_{V a p} \Delta h_{V a p}-\dot{\omega}_{P y r} \Delta h_{P y r}+\alpha_{S G} \Delta h_{C h a r} \dot{\omega}_{C h a r}
$$


The heat capacity $C_{S}^{m}$ characterizing locally each solid-fuel element is obtained from a mass fraction-weighted linear combination of the heat capacities of water, dry material, charcoal, and ash. $v_{A s h}=0.033$ is the mass fraction of ash in the solid fuel.

The rate of heat transfer $\dot{Q}_{S}$ received by a solid-fuel element results from convection and radiation heat exchanges with the hot gases and is given by [8-10]:

$$
\dot{Q}_{S}=h_{S} \alpha_{S} \sigma_{S}\left(T-T_{S}\right)+\alpha_{S} \sigma_{S}\left(J-4 \sigma T_{S}^{4}\right) / 4
$$

where $T$ is the temperature of the gas mixture at the surface of the solid fuel element, $\sigma=$ $5.67 \times 10^{-8} \mathrm{~W} / \mathrm{m}^{2} \cdot \mathrm{K}^{4}$ is the Stephan-Boltzmann constant, and $J$ is the total irradiance (fuel particles are assumed to behave as a black body). The convection heat transfer coefficient $h_{S}$ depends on the shape of the fuel particles and their characteristic length. For example, for a vegetation family with cylindrical shape particles, $h_{S}$ is obtained from:

$$
N u=\frac{h_{S} D}{\lambda}
$$

where $N u$ is Nusselt number based of the diameter $D$ of a cylindrical solid-particle, and $\lambda$ is the thermal conductivity of the gas mixture. Unlike previous works [8-10] that only accounted for forced convection, the Nusselt number in the present study accounts for both forced and natural convection and is given by:

$$
N u=\left(N u_{F C}^{2}+N u_{N C}^{2}\right)^{1 / 2}
$$

where $N u_{F C}$ and $N u_{N C}$ are respectively the forced convection and natural convection Nusselt numbers. $N u_{F C}$ and $N u_{N C}$ are correlated to Prandtl number $P r$ of the gas mixture and to the Reynolds number $R e_{D}$ and to the Rayleigh number $R a_{D}$ based on the diameter $D$ of a cylindrical solid-particle as follows [26]:

$$
\begin{aligned}
& N u_{F C}= \begin{cases}\left(0.43+0.5 \operatorname{Re}_{D}^{0.5}\right) \operatorname{Pr}^{0.38} & \text { if } \operatorname{Re}_{D}<1300 \\
0.25 \operatorname{Re}_{D}^{0.6} \operatorname{Pr}^{0.38} & \text { if } R e_{D}>1300\end{cases} \\
& N u_{N C}^{1 / 2}=0.6+\frac{0.387 \operatorname{Ra}_{D}^{1 / 6}}{\left(1+\left(\frac{0.559}{P r}\right)^{9 / 16}\right)^{8 / 27}}
\end{aligned}
$$

Similar expressions are used to evaluate the convection heat transfer coefficient $h_{S}$ for flat solid-fuel particles.

\subsection{Gas-Phase Model}

The evolution of the state of the gaseous phase (composition, velocity, temperature ...) resulting from the thermal degradation of the vegetation and the combustion reactions is governed by the balance equations of mass, momentum, and energy. Since the flow regime 
380

is unsteady and fully turbulent in various regions of the computation domain, the equations are filtered using a mass-weighted average TRANS (Favre) formulation [27]. Hence, the filtered variables are governed by the following set of transport equations solved in the low Mach number approximation $[18,28]$ :

$$
\frac{D\left(\bar{\rho} \tilde{u}_{i}\right)}{D t}=-\frac{\partial \bar{P}}{\partial x_{i}}+\frac{\partial}{\partial x_{j}}\left[\bar{\mu}\left(\frac{\partial \tilde{u}_{i}}{\partial x_{j}}+\frac{\partial \tilde{u}_{j}}{\partial x_{i}}-\frac{2}{3} \frac{\partial \tilde{u}_{l}}{\partial x_{l}} \delta_{i j}\right)\right]-\frac{\partial}{\partial x_{j}}\left(\overline{\rho u_{l}^{\prime} u_{\jmath}^{\prime}}\right)+\left(\rho-\rho_{0}\right) g_{i}-\sum_{m} F_{D i}^{m}
$$

$$
\frac{D(\bar{\rho} \tilde{h})}{D t}=-\frac{\partial \bar{P}_{t h}}{\partial t}+\frac{\partial}{\partial x_{j}}\left[\frac{\bar{\mu}}{\operatorname{Pr}} \frac{\partial \tilde{T}}{\partial x_{j}}\right]-\frac{\partial}{\partial x_{j}}\left(\overline{\rho u_{l}^{\prime} h^{\prime}}\right)+\left(1-\alpha_{S G}\right) \Delta h_{C h a r} \sum_{m} \dot{\omega}_{C h a r}
$$

$$
+\sum_{m} \sum_{\alpha} \dot{M}_{\alpha}^{m} \tilde{h}_{\alpha}+\sum_{m} \dot{Q}_{S, \text { Conv }}^{m}+\alpha_{G} \sigma_{G}\left(J-4 \sigma \tilde{T}^{4}\right)
$$

$$
\frac{D\left(\bar{\rho} \tilde{Y}_{\alpha}\right)}{D t}=\frac{\partial}{\partial x_{j}}\left[\frac{\bar{\mu}}{S c} \frac{\partial \widetilde{Y}_{\alpha}}{\partial x_{j}}\right]-\frac{\partial}{\partial x_{j}}\left(\overline{\rho u_{\imath}^{\prime} Y_{\alpha}^{\prime}}\right)+\overline{\dot{\omega}_{\alpha}}+\sum_{m} \dot{M}_{\alpha}^{m}
$$

In these equations, all transported variables $\phi$ (density $\rho$, velocity components $u_{i}$, enthalpy $h$, and mass fractions $Y_{\alpha}$ of chemical species $\alpha$ : $\mathrm{CO}, \mathrm{O}_{2}, \mathrm{CO}_{2}, \mathrm{H}_{2} \mathrm{O}$, and $\mathrm{N}_{2}$ ) are decomposed as a sum of two contributions (Reynolds average + fluctuation: $\phi=\bar{\phi}+\phi^{\prime}$ ). On the other hand, Favre average is defined by: $\tilde{\phi}=\bar{\rho} \bar{\phi} / \bar{\rho}$. The differential operator $D / D t$ is defined as:

$$
\frac{D \phi}{D t}=\frac{\partial \phi}{\partial t}+\frac{\partial\left(\tilde{u}_{j} \phi\right)}{\partial x_{j}}
$$

The effective gas-phase density is defined as $\rho=\alpha_{G} \rho_{G}$, where $\rho_{G}$ is the density of the gasmixture and $\alpha_{G}$ is the volume fraction of the gaseous given by:

$$
\alpha_{G}=1-\sum_{m} \alpha_{S}^{m}
$$

where $\alpha_{S}^{m}$ is the volume fraction of family $m$ of solid-fuel particles. $\rho_{0}$ is the initial gas-phase density that is stratified due to gravity, $g_{i}$ being gravity component in $x_{i}$ direction. 
In the low Mach number approximation $[18,28]$, the acoustic filtering results in splitting the pressure of the gas-mixture, into three contributions: the dynamic pressure $P$ acting to balance inertial and external forces, the thermodynamic pressure $P_{t h}$ that is spatially homogeneous, and the hydrostatic pressure $P_{h s}$ that is time-independent and balances the initial density stratification.

In addition to the previous equations, the gas mixture is assumed to behave like an ideal gas. Hence, in low Mach number approximation, the gas-phase density is obtained from the following equation of state:

$$
\bar{P}_{t h}+\bar{P}_{h s}=\bar{\rho}\left(\sum_{\alpha} R_{\alpha} \tilde{Y}_{\alpha}\right) \tilde{T}
$$

where $R_{\alpha}$ (J/kg.K) is the ideal gas constant of chemical species $\alpha$ (universal gas constant divided by the molar mass).

The gaseous phase is assumed also to behave as a Newtonian fluid with a viscosity $\mu=\alpha_{G} \mu_{G}$, where $\mu_{G}$ is the dynamic viscosity of the gas mixture obtained from those of the chemical species $\left(\mu_{\alpha}\right)$ using a mass fraction-weighted linear combination. The dependence of $\mu_{\alpha}$ on temperature is governed by Sutherland law:

$$
\bar{\mu}_{\alpha}=\mu_{\alpha}^{r e f}\left(\frac{\tilde{T}}{T_{r e f}}\right)^{1.5}\left(\frac{T_{r e f}+S}{\bar{T}+S}\right)
$$

where $T_{\text {ref }}=273 \mathrm{~K}, S=110.4 \mathrm{~K}$, and $\mu_{\alpha}^{r e f}$ is the dynamic viscosities of the chemical species $\alpha$ at temperature $T_{r e f}$. As for dry air in standard conditions, Prandtl and Schmidt numbers are both set to 0.71 .

The term $F_{D i}^{m}$ denotes the $\mathrm{i}^{\text {th }}$ component of the drag force resulting from the dynamic interaction between the gas flow and the vegetation family $m$, it is given by:

$$
F_{D i}=\bar{\rho}|\widetilde{u}| \tilde{u}_{i} C_{D} a_{L}
$$

where $a_{L}=\alpha_{S} \sigma_{S} / 2$ is the leaves area density and $C_{D}$ is the drag coefficient obtained from correlations that depend on the particles shape of the vegetation family $m$ and on the Reynolds number based on the characteristic length of solid particles [26]. For example, for a vegetation family with cylindrical particles (twigs, needles), the evolution of the drag coefficient with Reynolds number based on the diameter $D$ of the particle is given by:

$$
C_{D}=1.17+\frac{5.93}{R e_{D}^{0.5}}
$$

Similar expressions are used to evaluate the drag coefficient $C_{D}$ for flat solid-fuel particles such as leaves.

The enthalpy $h$ of the gas mixture is obtained from a mass fraction-weighted linear combination of the enthalpies $h_{\alpha}$ of the chemical species $\left(\mathrm{CO}, \mathrm{O}_{2}, \mathrm{CO}_{2}, \mathrm{H}_{2} \mathrm{O}\right.$, and $\mathrm{N}_{2}$ ). For each chemical species, the enthalpy-temperature dependence is obtained from CHEMKIN thermodynamic data base [29]:

$$
\tilde{h}_{\alpha}=\beta_{\alpha, 0}+\sum_{n=1}^{5} \frac{1}{n} \beta_{\alpha, n} \widetilde{T}^{n}
$$


The term $\dot{Q}_{S, \text { Conv }}^{m}$ is the average rate of heat exchange by convection between the gas mixture and the solid-fuel family $m$, obtained from Eq. Error! Reference source not found.. $\sigma_{G}$ is the radiation absorption coefficient of the gas-soot mixture (including the absorption due to the presence of $\mathrm{CO}, \mathrm{CO}_{2}, \mathrm{H}_{2} \mathrm{O}$, and soot particles in the flame and the plumes [30]).

During the thermal decomposition of each solid-fuel family $m, \mathrm{O}_{2}$ gas is consumed, $\mathrm{CO}, \mathrm{CO}_{2}$, and $\mathrm{H}_{2} \mathrm{O}$ gases, and charcoal soot particles are produced at the following mass flow rates:

$$
\dot{M}_{O 2}=-v_{O 2}^{S} \dot{\omega}_{C h a r}
$$

$$
\dot{M}_{C O}=\left(1-v_{C h a r}-v_{C O 2}\right) \dot{\omega}_{P y r}+\left(2+v_{O 2}^{S}\right)(1-\varphi) \dot{\omega}_{\text {Char }}
$$

$$
\dot{M}_{C O 2}=v_{C O 2} \omega_{P y r}+\left(1+v_{O 2}^{S}\right)(2 \varphi-1) \dot{\omega}_{C h a r}
$$

$$
\dot{M}_{H 2 O}=\dot{\omega}_{V a p}
$$

$$
\dot{M}_{\text {Soot }}=v_{\text {Soot }} \dot{\omega}_{\text {Pyr }}
$$

These rates contribute to the source terms of the balance equations of mass, energy and chemical species. Finally, $\bar{\omega}_{\alpha}$ is the rate of production or destruction of the chemical species $\alpha$ resulting from combustion in the gaseous phase, this part is detailed in the combustion modeling section.

\subsection{Turbulence Modeling}

The double correlations representing the action of the fluctuations on the average transport equations are evaluated using the eddy viscosity concept [31] and generalized gradient diffusion of the scalar quantities $\phi$ as follows:

$$
\begin{aligned}
& -\overline{\rho u_{i}^{\prime} u_{j}^{\prime}}=\mu_{T}\left(\frac{\partial \tilde{u}_{i}}{\partial x_{j}}+\frac{\partial \tilde{u}_{j}}{\partial x_{i}}\right)-\frac{2}{3}\left(\mu_{T} \frac{\partial \tilde{u}_{l}}{\partial x_{l}}+\bar{\rho} k\right) \delta_{i j} \\
& -\overline{\rho u_{i}^{\prime} \phi^{\prime}}=\frac{\mu_{T}}{P r_{\phi}} \frac{\partial \tilde{\phi}}{\partial x_{i}}
\end{aligned}
$$

The turbulent viscosity $\mu_{T}$ is evaluated from the turbulent kinetic energy $k$ and its dissipation rate $\varepsilon$, and an adapted version of RNG- $k$ - $\varepsilon$ turbulence model in a high Reynolds number formulation is used [32].

$$
\mu_{T}=f_{\mu} \bar{\rho} C_{\mu} k^{2} / \varepsilon
$$

where $C_{\mu}=0.085$ and $f_{\mu}$ is a damping function given by Eq. (40) that accounts for lowReynolds-number effects and allows for a better handling of laminar flow regions.

$$
\ln \left(f_{\mu}\right)=-3.4\left(1+R e_{T} / 50\right)^{-2}
$$


$R e_{T}=\bar{\rho} k^{2} / \mu \varepsilon$ is the turbulent Reynolds number. In the limit of a high Reynolds number $\left(\mu / \mu_{T}<<1\right)$, Equations (19) and (20) result in: $\mu_{T}=\bar{\rho} C_{\mu} k^{2} / \varepsilon$.

The fields of the turbulent kinetic energy $k$ and its dissipation rate $\varepsilon$ are calculated from the two following transport equations:

$$
\begin{aligned}
\frac{D(\bar{\rho} k)}{D t}= & \frac{\partial}{\partial x_{j}}\left(\frac{\mu_{e}}{P r_{T}}\left(\frac{\partial k}{\partial x_{j}}\right)\right)+P_{k}+W_{k}-\bar{\rho} \varepsilon+\frac{1}{2} \bar{\rho}|\tilde{u}| \sum_{m} C_{D}^{m} \alpha_{S}^{m} \sigma_{S}^{m}\left(C_{P w}|\widetilde{u}|^{2}-C_{\varepsilon w} k\right) \\
\frac{D(\bar{\rho} \varepsilon)}{D t}= & \frac{\partial}{\partial x_{j}}\left(\frac{\mu_{e}}{P r_{T}}\left(\frac{\partial \varepsilon}{\partial x_{j}}\right)\right)+C_{1 \varepsilon}\left(\frac{P_{k}}{\tau}+C_{3 \varepsilon} \frac{W_{k}}{\tau}\right)+\left(C_{2 \varepsilon}+R\right) \bar{\rho} \frac{\varepsilon}{\tau} \\
& +\frac{1}{2} \bar{\rho}|\tilde{u}| \sum_{m} C_{D}^{m} \alpha_{S}^{m} \sigma_{S}^{m}\left(C_{P \varepsilon w}|\tilde{u}|^{2} \frac{\varepsilon}{k}-C_{D \varepsilon w} \varepsilon\right)
\end{aligned}
$$

The effective viscosity $\mu_{e}=\mu_{T}+\bar{\mu}, P_{k}$ and $W_{k}$ are respectively the terms contributing to the production of turbulence, due to shear and buoyancy effects [31], given by:

$$
P_{k}=-\overline{\rho u_{i}^{\prime} u_{j}^{\prime}} \frac{\partial \tilde{u}_{i}}{\partial x_{j}} \quad \text { and } \quad W_{k}=-\frac{\mu_{T}}{\bar{\rho} P r_{T}} \frac{\partial \bar{\rho}}{\partial x_{j}} g_{j}
$$

The effective Prandtl number is computed by iteration using Eq. (24) derived analytically in the RNG theory, where $P r_{0}=1$ for $P r=P r_{T}$, and $\operatorname{Pr} 0=P r=S c$ for $P r=P r_{\phi}$.

$$
\left|\frac{P r^{-1}-1.3929}{P r_{0}^{-1}-1.3929}\right|^{0.6321}\left|\frac{P r^{-1}+2.3929}{P r_{0}^{-1}+2.3929}\right|^{0.3679}=\frac{\bar{\mu}}{\mu_{e}}
$$

In Eq. (41) and (42), the terms proportional to the drag coefficient $C_{D}^{m}$ represent the production and destruction of turbulence resulting from the interaction between the boundary layer flow and the vegetation layer [33].

In the transport equation of $\varepsilon$, $\tau$ is the maximum between the integral turbulence time scale $(k / \varepsilon)$ and $6 \tau_{\eta}$, where $\tau_{\eta}=(\bar{\mu} / \bar{\rho} \varepsilon)^{1 / 2}$ is the Kolmogorov time scale. This treatment ensures that the time scale associated to the more powerful turbulent structures cannot be smaller than 6 times the turbulence dissipation scales.

The additional source term $R$ in the transport equation of $\varepsilon$ results from the RNG theory [32] and has extended the validity of this model to weak turbulent flow regions, i.e. near a wall or in the wake region, where turbulence is far from isotropic or homogeneous.

$$
R=C_{\mu} \eta^{3}\left(1-\eta / \eta_{0}\right) /\left(1+\beta \eta^{3}\right)
$$

where $\eta=\left(P_{k} / C_{\mu} \bar{\rho} \varepsilon\right)^{1 / 2}, \eta_{0}=4.38$ and $\beta=0.012$.

The following set of constants is introduced in the turbulence model [31]: $C_{1 \varepsilon}=1.42$ and $C_{2 \varepsilon}=1.68$. On the other hand, the degree to which $\varepsilon$ is affected by buoyancy is determined by the constant $C_{3 \varepsilon}$ calculated according to the following relation: 


$$
C_{3 \varepsilon}=\tanh \frac{\left|\tilde{u}_{j} g_{j}\right|}{\left(\tilde{u}_{j} \tilde{u}_{j}|g|^{2}-\left(\tilde{u}_{j} g_{j}\right)^{2}\right)^{0.5}}
$$

The terms including the drag coefficient in $k$ - $\varepsilon$ equations represent the action of the drag force resulting from the vegetation on the turbulent kinetic energy balance. The following set of constants is used in these terms [33]: $C_{P_{\varepsilon}}=0.8, C_{\varepsilon w}=4, C_{P_{\varepsilon w}}=1.5$, and $C_{P_{\varepsilon w}}=3.24$.

\subsection{Combustion Modeling}

Near the fire front and due to the presence of hot spot (hot gases, burning particles, etc.), $\mathrm{CO}$ gas and soot particles resulting from the decomposition of the vegetation react with the ambient air to produce $\mathrm{CO}_{2}$ gas according to the following equations written for $1 \mathrm{~kg}$ of fuel.

$$
\begin{aligned}
& \mathrm{CO}+v_{\mathrm{O} 2}^{G} \mathrm{O}_{2} \rightarrow\left(1+v_{\mathrm{O} 2}^{G}\right) \mathrm{CO}_{2} \\
& \mathrm{Soot}+v_{\mathrm{O} 2}^{\text {Soot }} \mathrm{O}_{2} \rightarrow\left(1+v_{\mathrm{O} 2}^{\text {Soot }}\right) \mathrm{CO}_{2}
\end{aligned}
$$

where $v_{O 2}^{G}=4 / 7$ and $v_{O 2}^{\text {Soot }}=8 / 3$ are the mass stoichiometric ratios.

Typical in gaseous combustion, the rate of consumption of $\mathrm{CO}$ gas is limited by two physical processes: at a small scale, by the time necessary for the chemical reaction to occur and, at a larger scale, by the time required for an effective mixing between the gaseous fuel and the ambient air. The rate of reaction governed by chemical kinetics is evaluated from an Arrhenius law as [34-36]:

$$
\overline{\dot{\omega}_{C O}^{A r}}=\bar{\rho}^{2} \tilde{Y}_{C O} \tilde{Y}_{O 2} K_{A r} \exp \left(-E_{A r} / R_{0} \tilde{T}\right)
$$

where the pre-exponential factor $K_{A r}=7 \times 10^{4} \mathrm{~m}^{3} / \mathrm{kg}$.s and the ratio of the activation energy with the ideal gas constant $E_{A r} / R_{0}=8000 \mathrm{~K}$. On the other hand, the mixing between the gaseous fuel (CO) and the ambient air is mainly piloted by the turbulent eddies located in the flaming zone. If the conditions are fully turbulent, the reaction rate can be written as a function of the local mass of reactants available for burning divided by the turbulent time scale (eddy dissipation combustion concept) [34]:

$$
\overline{\dot{\omega}_{C O}^{E D C}}=C_{A} \bar{\rho} / \tau_{m i x} \times \operatorname{Min}\left(\tilde{Y}_{C O}, \tilde{Y}_{O 2} / v_{O 2}^{G}\right)
$$

The parameter $C_{A}$ depends on the turbulent Reynolds number and is given by [34]: 


$$
C_{A}=\frac{23.6}{R e_{T}^{0.25}} \frac{\chi}{(1-\chi \gamma)}
$$

498

499

504

505

506

507

508

509

510

511

512

513

514

515

516

517

518

519

520

521

02

where $\gamma$ is the volume fraction of the small-scale turbulent structures and $\chi$ is the fraction occupied by the reaction zone inside these small structures, defined as follows:

$$
\gamma=9.7 \operatorname{Re}_{T}^{-0.75} \quad \chi=\frac{\operatorname{Re}_{T}^{0.25}}{2.13} \frac{\tilde{Y}_{C O 2} /\left(1+v_{O 2}^{G}\right)}{\tilde{Y}_{C O}+\tilde{Y}_{C O 2} /\left(1+v_{O 2}^{G}\right)}
$$

500 The turbulent time scale $\tau_{\text {mix }}$ is the maximum between the integral turbulence time scale $501(k / \varepsilon)$ and $6 \tau_{\eta}$, where $\tau_{\eta}=(\bar{\mu} / \bar{\rho} \varepsilon)^{1 / 2}$ is the Kolmogorov time scale.

The rate of combustion of the gaseous fuel is finally obtained from:

$$
\overline{\dot{\omega}_{C O}}=-\operatorname{Min}\left(\overline{\dot{\omega}_{C O}^{E D C}}, \overline{\dot{\omega}_{C O}^{A r}}\right)
$$

Consequently, the rates of destruction of $\mathrm{O}_{2}$ and of formation of $\mathrm{CO}_{2}$ resulting from the combustion of $\mathrm{CO}$ are according to Eq. (27): $\overline{\dot{\omega}}_{O 2}^{G}=v_{O 2}^{G} \overline{\dot{\omega}}_{C O}$ and $\overline{\dot{\omega}}_{C O 2}^{G}=-\left(1+v_{O 2}^{G}\right) \overline{\dot{\omega}}_{C O}$.

Because of the lack of information on soot production in natural fire, the production rate of soot is limited to that resulting from the pyrolysis process [7] given by Eq. Error! Reference source not found.. Assuming that the soot particles can be assimilated as carbon spheres of diameter $d_{\text {soot }}=1 \mu \mathrm{m}$ and density $\rho_{\text {Soot }}=1800 \mathrm{~kg} / \mathrm{m}^{3}$, the soot volume fraction field $\tilde{f}_{v}$ is evaluated from the following transport equation [36, 37]:

$$
\frac{D\left(\bar{\rho} \tilde{f}_{v}\right)}{D t}=-\frac{\partial}{\partial x_{j}}\left(\bar{\rho} \tilde{u}_{j}^{t h} \tilde{f}_{v}\right)-\frac{\partial}{\partial x_{j}}\left(\overline{\rho u_{l}^{\prime} f_{v}^{\prime}}\right)+\overline{\dot{\omega}_{\alpha}}+\frac{\bar{\rho}}{\rho_{\text {Soot }}} \sum_{m}\left(\dot{M}_{\text {Soot }}^{m}-\overline{\dot{\omega}_{\text {Soot }}}\right)
$$

We can notice that the transport of the soot particles by convection is enhanced by the temperature gradient (thermophoretic velocity $\tilde{u}_{j}^{t h}$ ) defined by:

$$
\tilde{u}_{j}^{\text {th }}=-0.54 \frac{\bar{\mu}}{\bar{\rho}} \frac{\partial(\ln \tilde{T})}{\partial x_{j}}
$$

The term $\overline{\dot{\omega}}_{\text {Soot }}$ results from soot oxidation and is evaluated from the rate for oxidation of pyrolytic graphite by $\mathrm{O}_{2}$ as follows [36]:

$$
\overline{\dot{\omega}_{\text {Soot }}}=12 \tilde{f}_{v} \sigma_{\text {Soot }}\left[\frac{k_{A} \bar{P}_{O 2}}{1+k_{Z} \bar{P}_{O 2}} \zeta+k_{B} \bar{P}_{O 2}(1-\zeta)\right] \text { with } \zeta=\left(1+k_{T} / k_{B} \bar{P}_{O 2}\right)^{-1}
$$


where $\sigma_{\text {Soot }}=6 / d_{\text {Soot }}$ is the surface area-to-volume ratio of soot particles, $P_{02}$ is the partial pressure of oxygen, and the various reaction rates $k_{A}, k_{B}, k_{T}$, and $k_{z}$ depend on temperature according to Arrhenius laws [36]. The rates of destruction of $\mathrm{O}_{2}$ and of formation of $\mathrm{CO}_{2}$ resulting from the soot oxidation are estimated according to Eq. (28): $\overline{\hat{\omega}}_{O 2}^{\text {Soot }}=-v_{O 2}^{\text {Soot }} \bar{\omega}_{\text {Soot }}$ and $\bar{\omega}_{\mathrm{CO} 2}^{\text {Soot }}=\left(1+v_{O 2}^{\text {Soot }}\right) \overline{\dot{\omega}}_{\text {Soot }}$.

\subsection{Radiation Heat Transfer}

Radiation is one of the most important heat transfer mechanisms contributing to the propagation of a fire. It usually represents about $30 \%$ of the energy received by the vegetation located ahead of the fire front [20]. The total irradiance $J$ is calculated by integrating the radiation intensity $I$ in every direction:

$$
J=\int_{0}^{4 \pi} I d \Omega
$$

Radiation mainly results from soot particles produced in the flame and from the embers located behind the fire front. Accounting for these two contributions, the variation of the radiative intensity $I$ along an optical path $s$ verifies the following radiation transfer equation where $\sigma_{G}$ is the absorption coefficient of the gas-soot mixture.

$$
\frac{d\left(\alpha_{G} I\right)}{d s}=\alpha_{G} \sigma_{G}\left(\frac{\sigma \widetilde{T}^{4}}{\pi}-I\right)+\sum_{m} \frac{\alpha_{S}^{m} \sigma_{S}^{m}}{4}\left(\frac{\sigma\left(T_{S}^{m}\right)^{4}}{\pi}-I\right)
$$

The absorption coefficient $\sigma_{G}$ depends on the amounts of evaporation and combustion products $\left(\mathrm{CO}_{2}\right.$ and $\left.\mathrm{H}_{2} \mathrm{O}\right)$, on the gas mixture temperature, and of the soot volume fraction [39] according to the following relation:

$$
\sigma_{G}=0.1\left(\tilde{X}_{C O 2}+\tilde{X}_{H 2 O}\right)+1862 \tilde{f}_{v} \widetilde{T}
$$

where $\tilde{X}_{C O 2}$ and $\tilde{X}_{\mathrm{H}_{2} \mathrm{O}}$ are the mole fractions of $\mathrm{CO}_{2}$ and $\mathrm{H}_{2} \mathrm{O}$ respectively. A method adapted to optically thick media (very sooty flames), as well as to quasi-transparent media must be used to solve the radiation transfer equation (see next section).

\section{Numerical Method}

Describing the details of the numerical method used in FireStar3D is beyond the scope of this paper; only the outlines of the method are presented in this section, as well as the numerical improvements brought to the 2D version of the computational code (namely FireStar2D). Two independent meshes are used to solve the mathematical model: a first one for the gaseous phase and a second one for the solid phase (vegetation).

The transport equations in the gaseous phase Error! Reference source not found. to (11), (23), (24), and Error! Reference source not found. are solved numerically in a rectangular domain by a fully-implicit finite volume method using a segregated formulation [38] on a structured and non-uniform staggered-mesh. To avoid fire extinction within the 
solid-fuel bed for radiation-dominated fire propagation, the upper limit of the grid size ( $\Delta_{x}$, $\Delta_{y}, \Delta_{z}$ ) is given by [15] (both in the gas and the solid phase):

$$
\operatorname{Max}\left(\Delta_{x}, \Delta_{y}, \Delta_{z}\right)<4 / \sum_{m} \alpha_{S}^{m} \sigma_{S}^{m}
$$

where $4 / \alpha_{S}^{m} \sigma_{S}^{m}$ is the extinction length scale within the solid-fuel bed corresponding to vegetation family $m$. Previous simulations performed in worst conditions of propagation [41, 42], where the air flow was opposite to the direction of propagation, had shown that the verification of this criterion (60) near the fire front was sufficient to ensure a correct estimation of the heat transfer by radiation between the fire front and the solid fuel, and consequently to obtain grid-size-independent numerical results. On the other hand, the size of any cell adjacent to the wall should carefully be chosen such that its center fall within the log-law region of a turbulent boundary layer [40] where the rate of turbulence production equals the rate of dissipation (equilibrium turbulence). This condition is fulfilled if dimensionless distance to the wall of the cell center defined by Eq. (61) satisfies the constraint $11.5<y+<500$, and this during the entire simulation time.

$$
y^{+}=\frac{\bar{\rho} C_{\mu}^{1 / 4} k^{1 / 2} y}{\mu}
$$

Wall-function formulae [40] covering both the viscous sub-layer and the log-law region were then used to estimate wall shear-stresses and fluxes. An important improvement brought to the 2D version is space and time discretization. The first-order fixed-time step time discretization of the 2D version was replaced by a third order Euler scheme with variable time steps. The time steps are obtained from an adaptive time stepping algorithm based on the estimation of the truncation error [43]. The second-order space discretization was replaced by the third order QUICK scheme [44] with flux limiters for convection terms, while diffusion terms were approached by central difference [40]. This improvement results in a higher accuracy or in larger time steps and a coarser mesh for a desired accuracy (specified by a prescribed truncation error). It also allows the time step to varie automatically between two prescribed limits according to the characteristic time scale of the predominant physics. Since the momentum and the continuity equations are solved separately, the coupling between the velocity field and the pressure field is ensured using a PISO algorithm [45]. The linear systems resulting from the discretization of the transport equations are solved using a bi-conjugate gradient stabilized method with Jacobi preconditioner [46], while pressure equation is solved using a conjugate gradient method with implicit modified ILU (MILU) preconditioner [47]. This is another important improvement brought to the $2 \mathrm{D}$ version of the computational code, which decreases by a factor 5 to 6 the CPU time required to solve the pressure equation that consumed in the previous works [8-10] more than $70 \%$ of the total CPU time. In addition, the pressure equation is preconditioned using the artificial compressibility method [48]. The radiative transport equation (58) is solved using a Discrete Ordinate Method, consisting in the 
decomposition of the radiation intensity in a finite number of directions and a GaussLegendre quadrature [49].

Embedded in the fluid domain, the solid-phase domain is also subdivided into solid-fuel elements using a rectangular uniform mesh. Each element could contain several vegetation families, and the state of each family $m$ is characterized by its own set of variables: $\alpha_{S}^{m}, \rho_{S}^{m}$, $M^{m}, \sigma_{S}^{m}$, composition, etc. As indicated previously, the size of the solid-phase mesh $\left(\Delta_{x}^{S}, \Delta_{y}^{S}\right.$, $\Delta_{z}^{S}$ ) is also chosen according to Eq. (35), and Eqs. Error! Reference source not found. to Error! Reference source not found. are solved for each vegetation family $m$ and for each solid-fuel element separately using a fourth-order Runge-Kutta method (RK4).

From the implementation point of view, the solver was parallelized [47] and optimized [50] using the APIs OpenMP and HMPP directives (suitable for shared memory platforms). This is another feature specific to FireStar3D by comparison with its 2D counterpart. FireStar3D is operational on high-performance computing machines consisting of a SMP node using modern processors with INTEL Xeon Phi co-processors and NVIDIA graphic cards. The Navier-Stokes low-Mach-number solver of FireStar3D has been extensively validated on several benchmarks of laminar and turbulent natural convection and forced convection including non-Boussinesq effects [50], and the multiphase part was tested for neutrally stratified atmospheric flow within and above a sparse forest canopy [51].

\section{Fire Propagation in Wind Tunnel}

After testing the hydrodynamic and the multiphase modules of FireStar3D on academic configurations [50,51], the first validation of the entire model was performed by simulating some experimental fires conducted in the wind-tunnel of Missoula Fire Sciences Laboratory [12]. This choice can be justified by the fact that these experiments were conducted under well-controlled experimental conditions that guaranteed a good reproducibility of the results [12], this concerns both the structure and the state of the fuelbed (homogeneity, depth, moisture content, density, load ...) and the turbulent flow in the wind tunnel. As indicated by Catchpole et al. [12], the length of the test section $(8 \mathrm{~m})$ was long enough to reach a quasi-steady state of fire propagation, and over $4.5 \mathrm{~m}$ of propagation, the variation of the rate of spread was about $10 \%$, which can be considered as satisfactory. 15 duly chosen experiments of fuelbed fire carried out by Catchpole et al. [12] were reproduced numerically. The comparison between the numerical results and the experimental data was limited to the rate of spread since this was the only available output from these experiments. Nevertheless, this integral variable can be considered a good indicator of the overall fire behavior. Also, at low fuel moisture content (less than $20 \%$ ), all the solid fuel was consumed, thus the knowledge of the rate of spread allows also to evaluate the fire intensity.

\subsection{Fuelbed Configuration}


As shown in Fig. 1, the fuelbed was divided into two zones having the same physical characteristics; however, only zone (2) was thermally degradable, i.e. equations Error! Reference source not found. to Error! Reference source not found. of the solid-fuel model were only solved for zone (2). Zone (1) (2m long) was added to account for a wire mesh spoiler used in the experiment and placed transversely on the floor of the wind tunnel to initiate more rapidly the turbulent boundary layer flow [12]. Also, vertical strips of metal sheeting (matching the fuelbed height) were placed in the experiments along each side of the tray to mimic a wider fire front by preventing in-drafts into the combustion zone. These strips were accounted for numerically by placing vertical baffles along each side of the fuelbed (see Fig. 1); the velocity component normal to the baffles ( $y$ component) was set to zero, while a friction coefficient $C_{f}=0.01$ was introduced in the momentum equations of the velocity components tangential to the baffles ( $x$ and $z$ components). This friction coefficient is twice that of a turbulent flow over a smooth flat plate (to account for both sides of the baffles) at a Reynolds number of about $5 \times 10^{5}$. Nevertheless, doubling the value of $C_{f}$ or dividing it by 2 had no noticeable effect on the fires dynamics.

Before ignition, simulations were run long enough using Neumann conditions at the open boundaries while imposing a negative artificial pressure gradient in the $x$-momentum equation. This artificial pressure gradient was adjusted automatically by the solver in order to reach at each time step the desired wind speed at the center of the wind tunnel entrance that was imposed in the experiment. This phase was maintained for 5 seconds, which was the time required for reaching a quasi-steady turbulent flow. Then, the turbulent velocity profile, obtained at the wind tunnel entrance, was applied at the inlet of the domain during the remaining time of simulation. At $t=5 \mathrm{~s}$, fire was set at the entrance of zone (2) by injecting carbon monoxide at $1600 \mathrm{~K}$ from the bottom of the computation domain for another 5 seconds (hence reproducing a porous gas burner). The injection surface lies between $x=2 \mathrm{~m}$ and $x=2.16 \mathrm{~m}$, and along the entire width of zone (2). According to the equation (62), at $t=5 \mathrm{~s}$ the average injection speed is maximum $\left(V_{j}=10 \mathrm{~cm} / \mathrm{s}\right)$, then it decreases linearly with the burned mass of dry material $\left(m_{b}\right)$ in order to avoid destabilizing the fire-front by suddenly ceasing the injection.

$$
V_{j}(\mathrm{~cm} / \mathrm{s})=10 \times\left(1-m_{b} / m_{b 0}\right)
$$

where $m_{b 0}$ is the initial mass of dry material located above the burner (i.e. the mass of dry material inside the volume $V_{b o}=0.16 \times 1 \times \delta \mathrm{m}^{3}$ ). Equation (62) was used between $t=5 \mathrm{~s}$ and $t=10 \mathrm{~s}$ as long as $V_{j}$ had remained positive, but the injection of carbon monoxide was stopped once $V_{j}$ had reached zero during this time interval. 


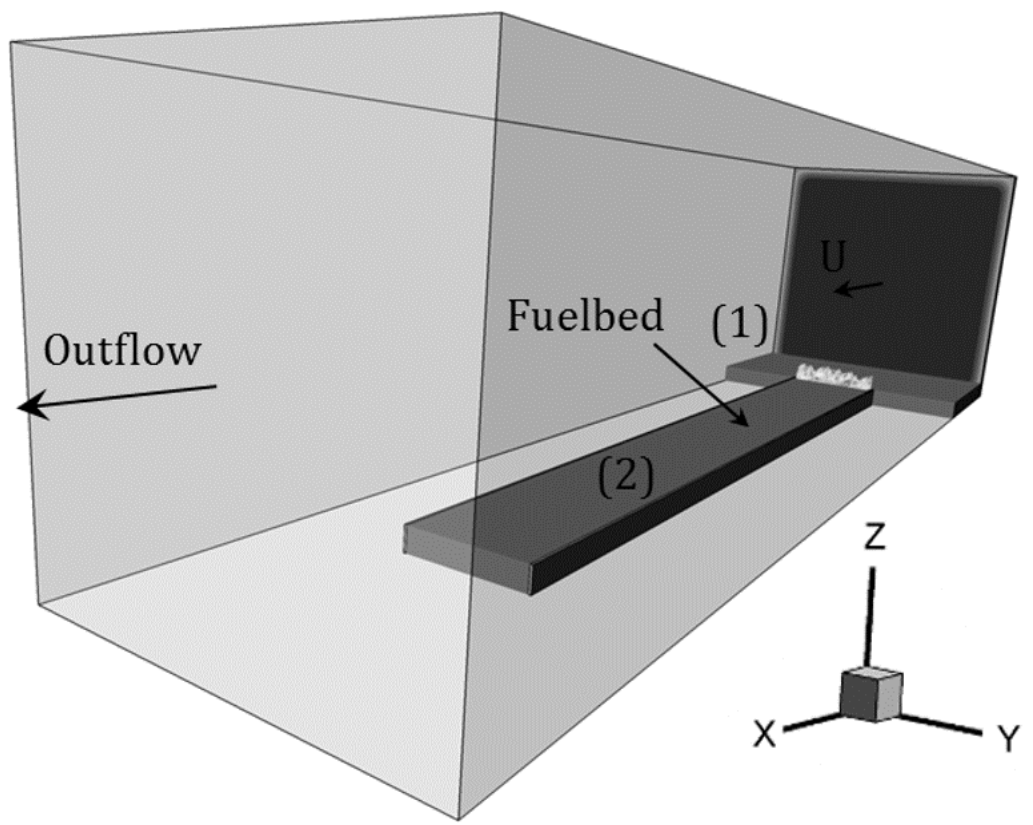

Fig. 1. Perspective view of the computation domain corresponding to Catchpole et al. experiment. The flow domain dimensions are $12 \times 3 \times 3 \mathrm{~m}^{3}$ and those of the fuelbed are $10 \times 1 \times \delta \mathrm{m}^{3}$ (the fuelbed thickness $\delta=15.2$ or $20.3 \mathrm{~cm}$ ). The fuelbed is divided into two zones, only zone (2) $(2 \mathrm{~m}<x<10 \mathrm{~m})$ is thermally degradable, vertical baffles ( $0.25 \mathrm{~m}$ high) are placed along both sides of zone (2) and fire is set at its entrance.

660

661

662

663

664

665

666

667

668

669

670

671

672

673

674

675

676

The simulations were conducted for three types of solid fuel, namely: Populus tranulos regular excelsior (dry material density $\rho_{\text {Dry }}=398 \mathrm{~kg} / \mathrm{m}^{3}$, surface-to-volume ratio $\sigma_{S}=7596$ $\mathrm{m}^{-1}$, and pyrolysis heat release $\Delta h_{P y r}=711 \mathrm{~kJ} / \mathrm{kg}$ ), Populus tranulos - coarse excelsior ( $\rho_{\text {Dry }}$ $=398 \mathrm{~kg} / \mathrm{m}^{3}, \sigma_{S}=3092 \mathrm{~m}^{-1}$, and $\Delta h_{P y r}=711 \mathrm{~kJ} / \mathrm{kg}$ ), and Pinus ponderosa heartwood sticks $\left(\rho_{\text {Dry }}=442 \mathrm{~kg} / \mathrm{m}^{3}, \sigma_{S}=630 \mathrm{~m}^{-1}\right.$, and $\left.\Delta h_{P y r}=659 \mathrm{~kJ} / \mathrm{kg}\right)$. This choice allowed to cover both the fine fuel case and the threshold fine/coarse fuel one. The simulations correspond to experiments EXMC 23, 24, 28, 36, 48, 5I, 69, 82, EXSC 64, 65, 73, 7D, and MF 37, 38, 54 carried out by Catchpole et al. [14]. These 15 experiments, whose main physical data are shown in Tab. 2, were chosen to test the dependence of the ROS on wind speed $U$ and on the fuelbed characteristics (fuel type, fuel moisture-content $M$, solid-fuel volume-fraction $\alpha_{S}$, and fuelbed depth $\delta$ ). These experiments were also selected to obtain a wide range of fuelbed optical thickness, defined as the ratio between the depth of the fuelbed and the extinction length scale $\tau_{o p t}=\alpha_{s} \sigma_{s} \delta / 4$, that varies by an order of magnitude. Finally, it should be noted for the MF series (Pinus ponderosa heartwood sticks) that $\sigma_{S}=630 \mathrm{~m}^{-1}$ corresponds to cylindrical particles having an average diameter of $6.3 \mathrm{~mm}$, which is about the threshold size between thermally thin and thick particles. 


\begin{tabular}{llccccc}
\hline & & $\alpha_{S}$ & $\delta(\mathrm{m})$ & $U(\mathrm{~m} / \mathrm{s})$ & $M(\%)$ & $\tau_{\text {opt }}$ \\
\hline 1 & EXMC23 & 0.005 & 0.203 & 2.68 & 5.5 & 1.93 \\
2 & EXMC24 & 0.005 & 0.203 & 0.89 & 5.2 & 1.93 \\
3 & EXMC28 & 0.005 & 0.203 & 1.79 & 5.4 & 1.93 \\
4 & EXMC36 & 0.005 & 0.203 & 2.68 & 10.1 & 1.93 \\
5 & EXMC48 & 0.005 & 0.203 & 2.68 & 18.1 & 1.93 \\
6 & EXMC5I & 0.005 & 0.152 & 2.68 & 4.5 & 1.44 \\
7 & EXMC69 & 0.005 & 0.203 & 2.68 & 3.0 & 1.93 \\
8 & EXMC82 & 0.015 & 0.203 & 1.79 & 4.9 & 5.78 \\
9 & EXSC64 & 0.010 & 0.152 & 1.34 & 4.1 & 1.17 \\
10 & EXSC65 & 0.015 & 0.203 & 2.68 & 3.1 & 2.35 \\
11 & EXSC73 & 0.015 & 0.203 & 2.68 & 23.6 & 2.35 \\
12 & EXSC7D & 0.015 & 0.203 & 1.34 & 7.5 & 2.35 \\
13 & MF37 & 0.018 & 0.152 & 0.89 & 6.5 & 0.43 \\
14 & MF38 & 0.018 & 0.152 & 2.68 & 6.2 & 0.43 \\
15 & MF54 & 0.009 & 0.152 & 2.68 & 5.9 & 0.22 \\
\hline
\end{tabular}

Tab. 2. Catchpole et al. experiments chosen to show the effect of solid-fuel characteristics, of fuelbed height, and of wind speed on fire spread dynamics. EXMC series: Populus tranulos (regular excelsior), EXSC series: Populus tranulos (coarse excelsior), MF series: Pinus ponderosa heartwood sticks. $\delta$ fuelbed depth, $U$ - wind speed, $\alpha_{s}$ - solid-fuel volume fraction, $M$ - fuel moisture content, $\tau_{\text {opt }}$ - fuelbed optical thickness.

680

681

682

683

684

685

686

687

688

689

690

691

692

693

694

695

696
As indicated in a previous section, a uniform mesh was used for the solid domain with a grid size $\left(\Delta_{x}^{S}, \Delta_{y}^{S}, \Delta_{z}^{S}\right)=(2 \mathrm{~cm}, 1.25 \mathrm{~cm}, 1.69 \mathrm{~cm})$, while a wall-refined mesh of $300 \times 80 \times 62$ grid points was used for the fluid domain. Within the vegetation zone, the fluid-domain mesh was uniform and twice coarser (in each direction) than the solid-domain mesh, whereas it was gradually refined toward the rigid walls according to geometric progression. The grid size of the fluid-domain varied between $2.5 \mathrm{~cm}$ and $8.7 \mathrm{~cm}$, while the value of $4 / \alpha_{\mathrm{S}} \sigma_{\mathrm{S}}$, representing the extinction length scale within the fuelbed, varies from $3.51 \mathrm{~cm}$ (for EXMC82) to $70.5 \mathrm{~cm}$ (for MF54); hence, the constraint given by Eq. (35) is respected in all directions for all simulations. For the adaptive time-stepping strategy, the minimum and maximum time-step values were set to $10^{-3}$ and $10^{-2} \mathrm{~s}$ respectively, and the desired level of truncation error was set to $10^{-4}$. Finally, at each time step, the global convergence was assumed to be reach when the $\mathrm{L}_{2}$-norms of all transport equations residuals had reached $10^{-5}$ in normalized form and $10^{-4}$ in non-normalized form. Typically, 30 seconds of simulation time required in average 96 hours of CPU time on a 16-processor shared-memory workstation. 
697

698

699

700

701

702

703

704

705

706

707

708

709

710

711

712

713

714

715

716

717

718

719

720

721

722

\subsection{Results and Discussion}

Figure 2 shows the gas temperature and the flow structure (streamlines), obtained numerically $15 \mathrm{~s}$ and $25 \mathrm{~s}$ after ignition in the case of experiment EXMC23. We notice the strong 3D effects characterizing the behavior of the fire, with a head of the fire front structured as a tip and the gas flow bypassing laterally the flaming zone (clearly shown at $t=20 \mathrm{~s}$ and $\mathrm{t}=30 \mathrm{~s}$ in the horizontal plane). We also notice (in Fig. 2-b in the vertical median plane) the existence of a reverse flow, drawing in fresh air from the wind-tunnel exit into the flaming zone; this shows the potential of FireStar3D in handling backflow situation (i.e. as in the experiments, the exit of the wind-tunnel was not treated as an imposed outflow boundary conditions, the model allows for a backflow to occur at the exit of the wind-tunnel as a result of the mass balance). This feature must be underlined, it can be very appreciable in simulating some particular situations, such as fires propagating in no-wind conditions, back-fires, and counter-fires. In comparison, the outflow conditions in FIRETEC are forced to match the inlet conditions calculated before fire ignition, thus violating the total mass balance for not accounting for the additional mass source resulting from the decomposition of the solid fuel and for the modifications induced on the flow by the development of the thermal plumes [52]. The procedure used in Firestar3D is thus similar to that used in WFDS; this difference in handling outflow conditions, between FireStar3D/WFDS on one hand and FIRETEC on the other, can explain the difference in efficiency between these 3D codes and in their ability to simulate some particular configurations, such as backfire situations $[52,53]$. 
(a)

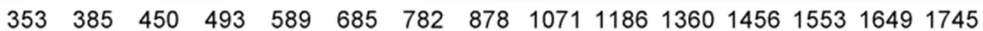
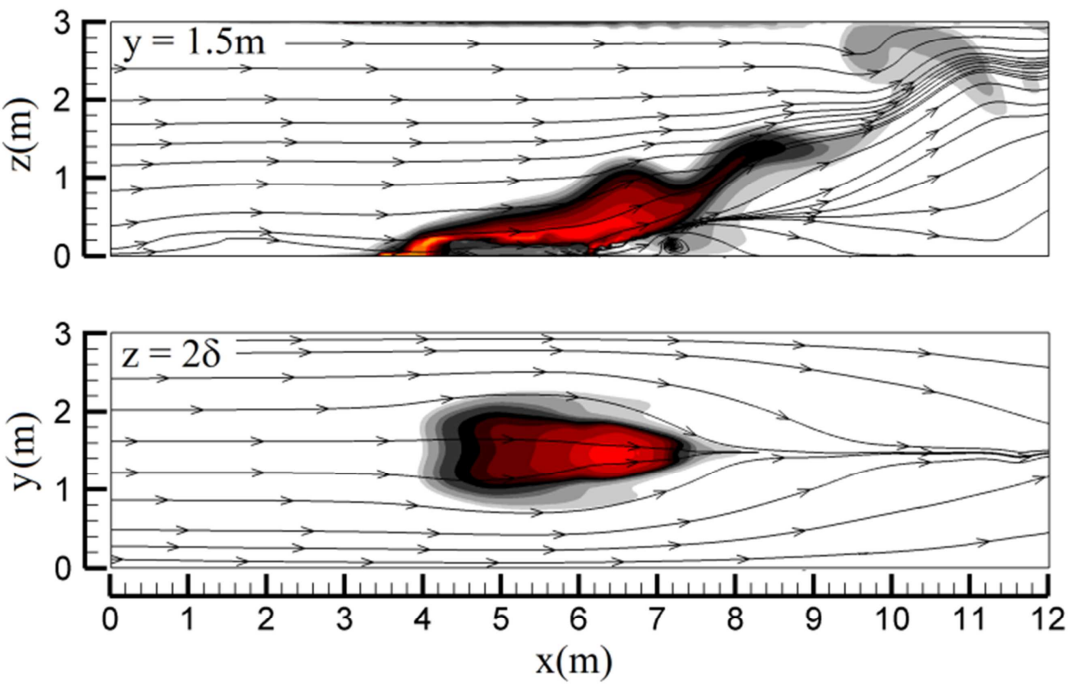

$\begin{array}{lllllllllllllll}353 & 385 & 450 & 493 & 589 & 685 & 782 & 878 & 1071 & 1186 & 1360 & 1456 & 1553 & 1649 & 1745\end{array}$

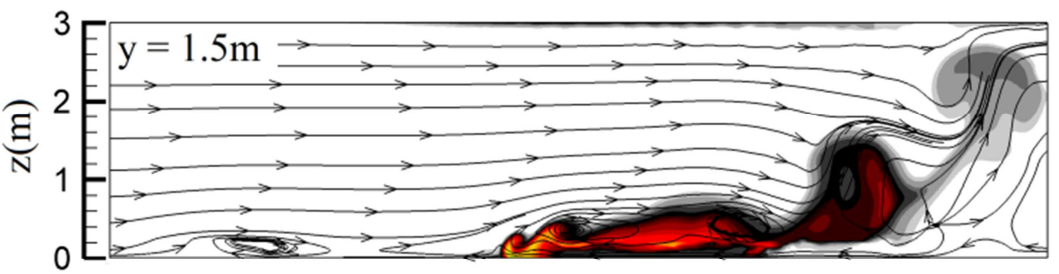

(b)

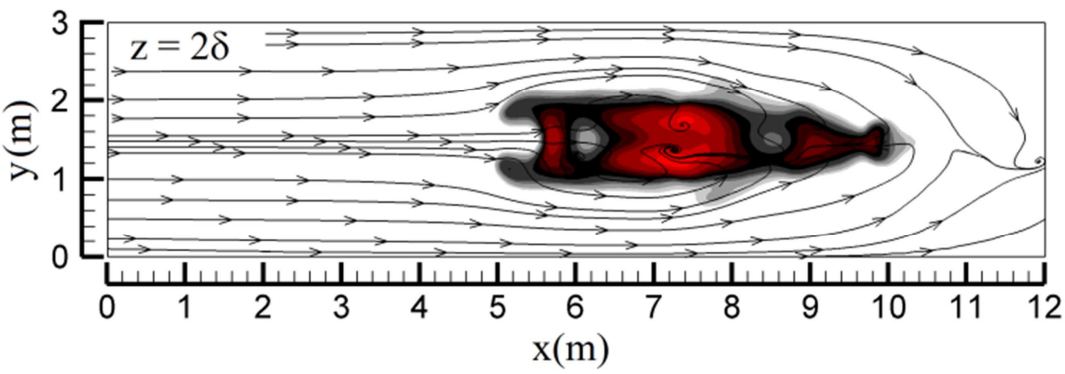

Fig. 2. Temperature fields and streamlines obtained numerically at $t=20 \mathrm{~s}(\mathrm{a})$ and at $\mathrm{t}=30 \mathrm{~s}$ (b) in the case of experiment EXMC23 of Catchpole et al. [12] (regular excelsior, wind speed of $U=2.68 \mathrm{~m} / \mathrm{s}$, moisture content $M=5.5 \%$, see Tab. 2 for more details). Top: solution in the vertical median plane $(\mathrm{y}=1.5 \mathrm{~m})$, bottom: solution in the horizontal plane at $\mathrm{z}=2 \delta$. 

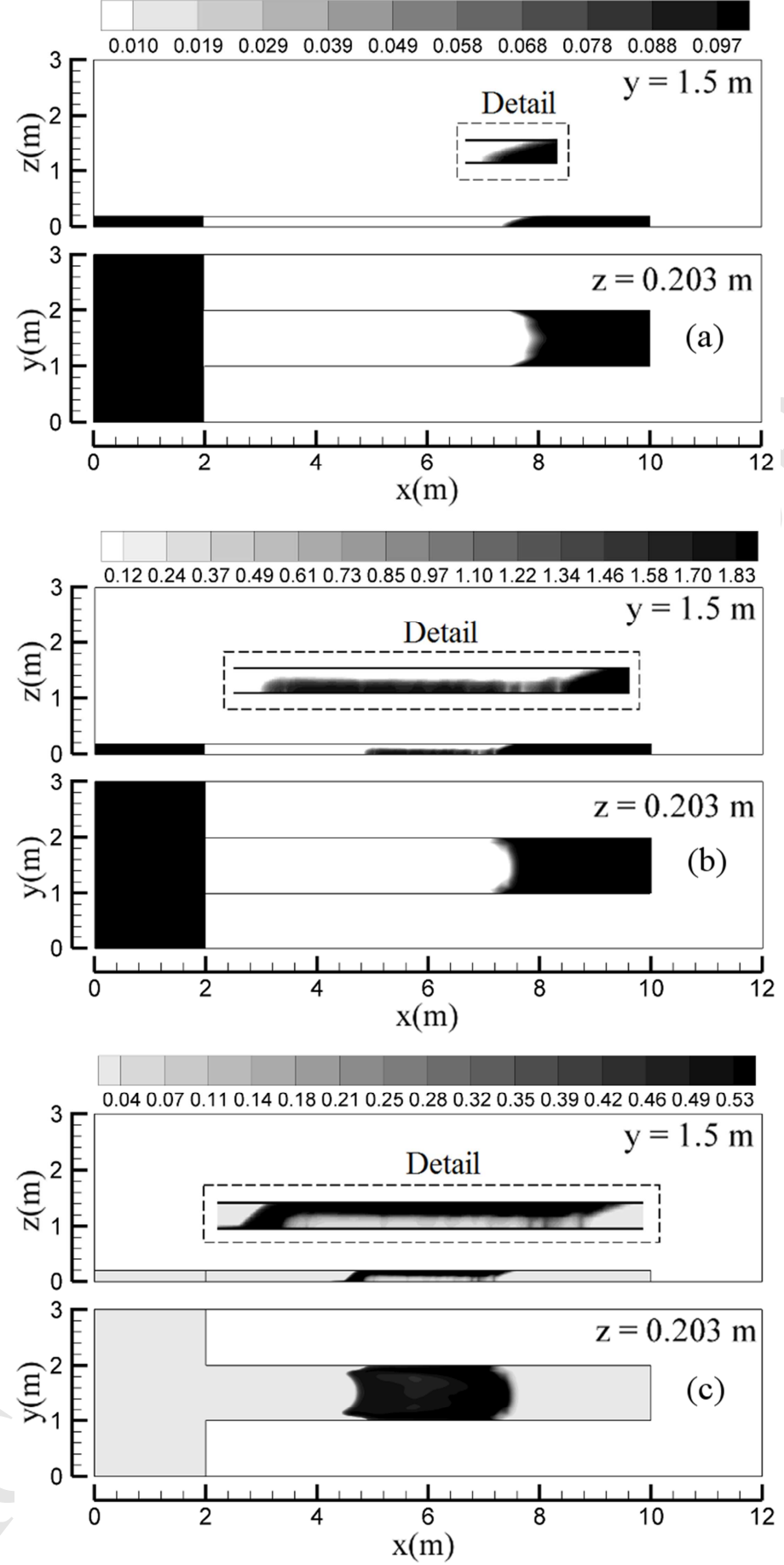

Fig. 3. Distributions of the solid-fuel composition in effective density $\left(\mathrm{kg} / \mathrm{m}^{3}\right)$ at the surface of the fuelbed $(z=0.203 \mathrm{~m})$ and in the vertical median plan $(y=1.5$ $\mathrm{m})$, obtained at $t=25 \mathrm{~s}$, corresponding to experiment EXMC23 of Catchpole et al. [12] (see Tab. 2 for details): (a) water $\boldsymbol{\rho}_{\boldsymbol{S}}^{\boldsymbol{e}} Y_{H 2 O}$, (b) dry fuel (wood) $\boldsymbol{\rho}_{\boldsymbol{S}}^{\boldsymbol{e}} Y_{\text {Dry, }}$, and (c) charcoal $\boldsymbol{\rho}_{\boldsymbol{S}}^{\boldsymbol{e}} Y_{\text {Char. }}$. 
Figure 3 reports the distributions of solid-fuel composition (in terms of effective density of water, dry fuel and charcoal) within the fuelbed. We notice that while the dehydration process took place in the entire depth of the fuelbed (Fig. 3-a), the pyrolysis process was characterized with more inertia, it took place within the upper layer of the fuelbed first (Figs. 3-b and 3-c), before affecting the whole solid-fuel layer. This result is closely related to the relative high value of the fuelbed optical thickness $\left(\tau_{\mathrm{opt}}=1.93\right.$ for experiment EXMC23); in this case, the solid fuel depth was about twice larger than the extinction length scale at which the radiation from the flame was absorbed. Whereas, for the same reasons detailed just above, the pyrolysis process took place within the entire depth of the fuelbed in the case of experiment MF54 $\left(\tau_{\mathrm{opt}}=0.215\right)$. The burning area at the surface of the fuelbed can be easily determined in Fig. 3-c from the distribution of charcoal mass-fraction, it extends approximately from $4.4 \mathrm{~m}$ to $7.6 \mathrm{~m}$. We can notice that at the end of charcoal combustion process (Fig.3-c) the totality of the fuel was consumed, which was effectively observed for this kind of experiment.

The comparison between the simulations and the experimental data was based on the rate of spread of fire or ROS (i.e. the average velocity of the pyrolysis front). For this purpose, fuelbed characteristics were monitored at the surface of the fuelbed at several positions along the direction of propagation of the fire $(y=1.5 \mathrm{~m}, \mathrm{z}=0.203 \mathrm{~m})$ as shown in Fig. 4, by analogy to the photocell tubes positioned at $0.5 \mathrm{~m}$ intervals in the experiments [12]. Figure 5 shows the time evolution of the fuelbed temperature at duly chosen points of Fig. 4; we clearly notice the phase of pyrolysis (between $400 \mathrm{~K}$ and $500 \mathrm{~K}$ according to the model) followed by the passage of the gaseous combustion front, the char combustion and the cooling phase at the back of the fire. The ROS could be easily estimated from Fig. 5 by measuring the average time required for the pyrolysis front (isotherm $500 \mathrm{~K}$ ) to move from a monitoring point to another (covering each time a fixed distance), in this case it was equal to $0.258 \mathrm{~m} / \mathrm{s}$. By comparing Fig. 3-c (obtained at $\mathrm{t}=25 \mathrm{~s}$ ) with the time history of the solid-fuel temperature shown in Fig. 5, and if we focused our analysis on point 8, we notice that the solid fuel is relatively hot (around $900 \mathrm{~K}$ ) due to the arrival of the flame front at $t=15 \mathrm{~s}$ (the ignition is clear with a sudden increase of temperature beyond $500 \mathrm{~K}$ ). Then at $t=28 \mathrm{~s}$, the curve of the solid-fuel temperature is characterized by a sharp peak that lies between $2000 \mathrm{~K}$ and $2250 \mathrm{~K}$. If we multiply the time gap (13 s) between these two events, by the average ROS $(0.258 \mathrm{~m} / \mathrm{s})$, we obtain a distance of $3.3 \mathrm{~m}$, which is more of less equal to the length of the charcoal region in Fig. 3-c. Despite the coarse nature of this analysis, it seems evident that the peak of temperature was due to an event occurring at the end of the charring combustion. The temperature peak $(2000-2250 \mathrm{~K})$ is not the result of heat transfer from the gas phase since, as shown by Fig. 6 , the gas temperature at the same point, 8, does not exceed $1800 \mathrm{~K}$, which is in agreement with the values measured experimentally in the persistent flame above a forest fuel burner [52]). The temperature peak is the result of thermal equilibrium of the solid-fuel particle, when the combustion 
energy partially absorbed by the particle (given by Eq. 8) is entirely evacuation by convection and radiation according to Eq. 16. The relatively short duration of this peak (T > $1200 \mathrm{~K}$ for about $0.54 \mathrm{~s}$ ) suggests that it occurs during the final regression phase of solidfuel particles from charcoal to ashes clearly shown in Fig. 7 by charcoal density. A closer view of Fig. 7 shows that, during the final step of the regression phase, the charcoal density decreased from $0.4 \mathrm{~kg} / \mathrm{m}^{3}$ the dry fuel located above the burner to 0 in $0.38 \mathrm{~s}$.

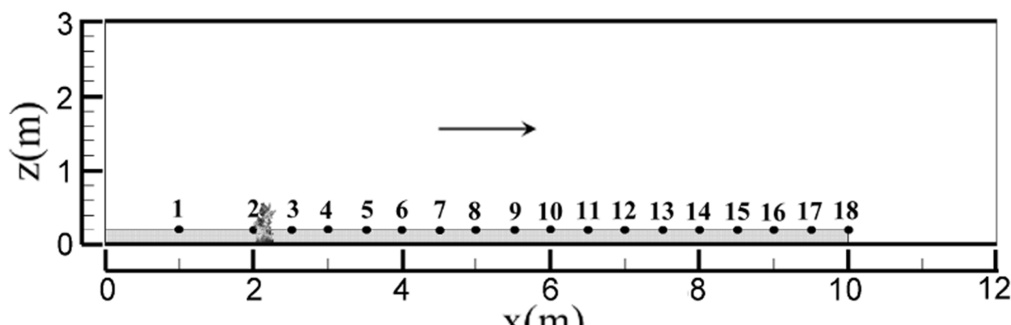

$\mathrm{x}(\mathrm{m})$

Fig. 4. Positions in the vertical median plan of the computation domain $(y=1.5 \mathrm{~m})$ where fuelbed characteristics are monitored during the simulations of Catchpole et al. experiments [12].

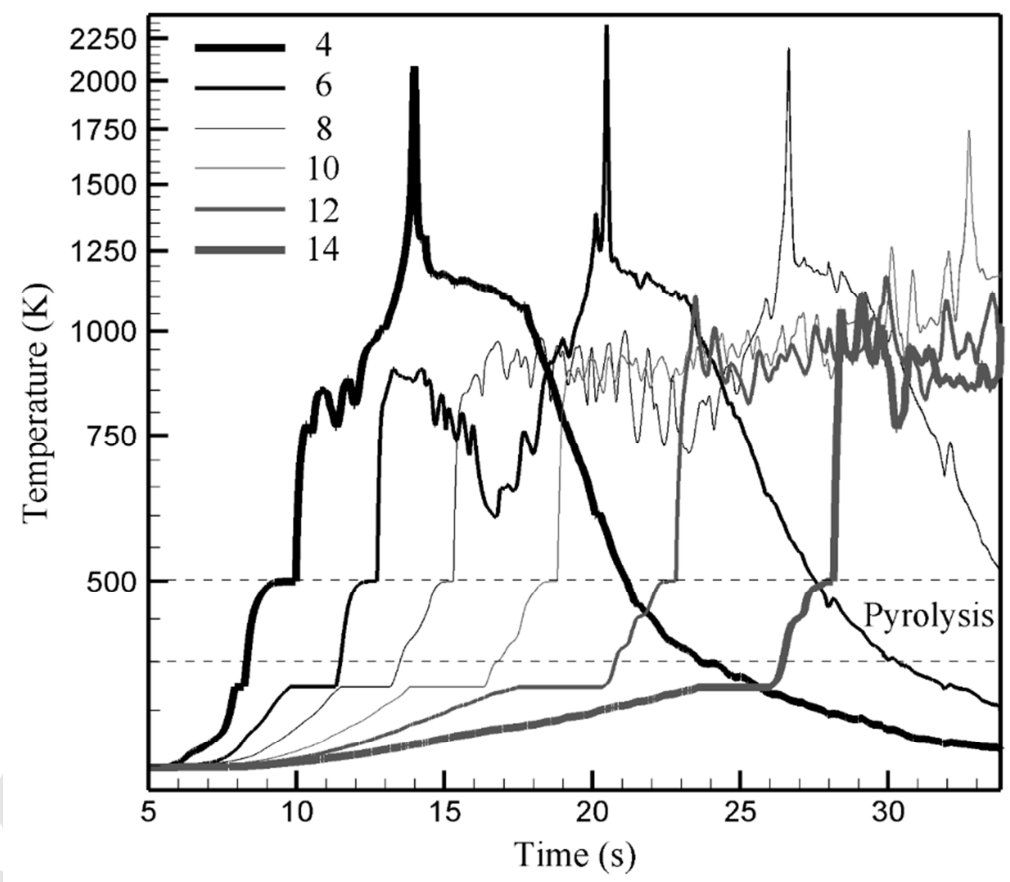

Fig. 5. Time-evolution of the solid fuel temperature (semi-logarithmic scale) at positions 4, 6, 8, 10,12, and 14 of Fig. 4, corresponding to experiment EXMC23 of Catchpole et al. [12] (see Tab. 2 for details). 


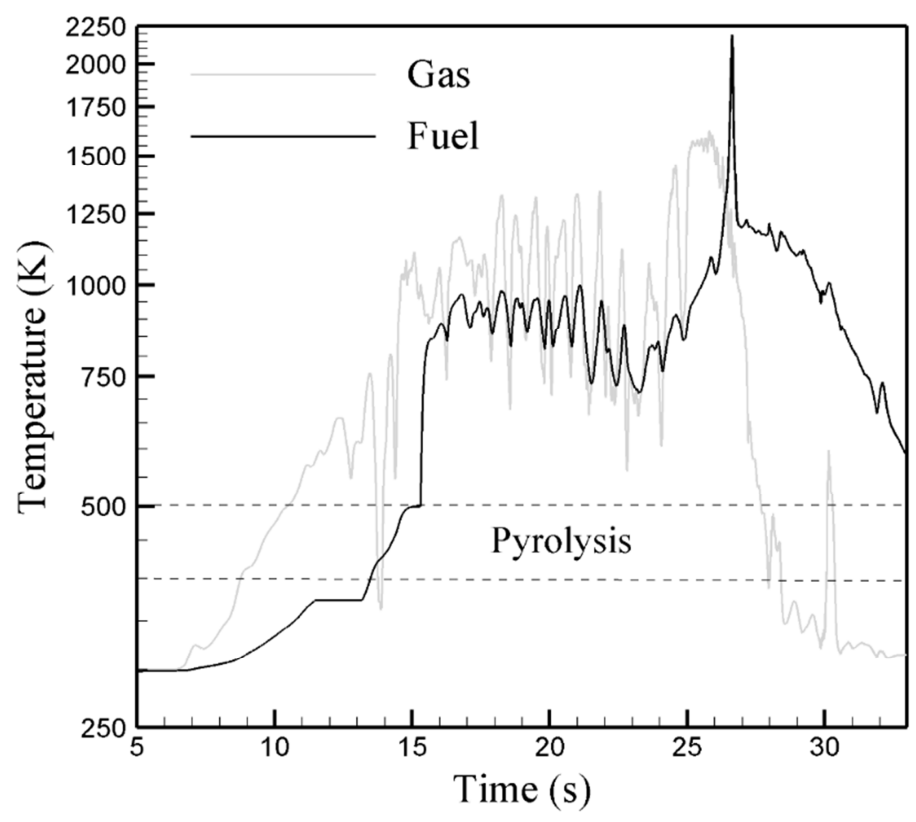

Fig. 6. Time-evolution of the solid fuel and gas temperatures at positions \#8 of Fig. 4, corresponding to experiment EXMC23 of Catchpole et al. [12] (see Tab. 2 for details).

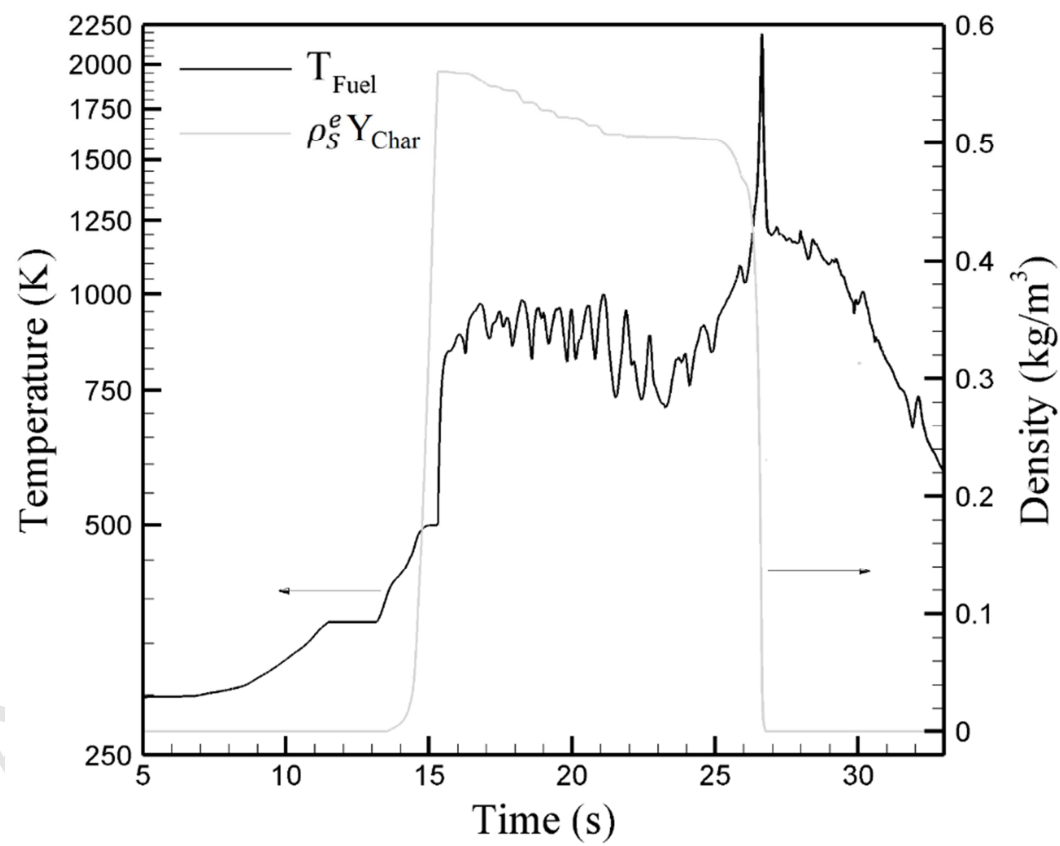

Fig. 7. Time-evolution of the solid-fuel temperature and the bulk charcoal density at positions \#8 of Fig. 4, corresponding to experiment EXMC23 of Catchpole et al. [12] (see Tab. 2 for details). 
Two main improvements were brought to FireStar3D model compared to previous works [8-10]: (i) accounting for incomplete combustion in the solid phase through variable $\varphi$ given by Eq. 5 that continuously varies with temperature between 0.5 (only CO is produced) and 1 (only $\mathrm{CO}_{2}$ is produced), (ii) accounting for natural convection in the expression of the Nusselt number given by Eq. 18. As shown by Fig. 8, both these new features result in a significant reduction of the maximum fuelbed temperature and consequently of the peak reached by the solid-particle temperature. Indeed, as mentioned before, the temperature peak is the result of thermal equilibrium of the solid-fuel particle. On one hand, accounting for incomplete combustion in the solid phase decreases $\Delta H_{\text {char }}$ (given by Eq. 9) and consequently the energy partially absorbed by the particle (given by Eq. 8); on the other hand, accounting for natural convection increases the convection heat transfer coefficient $h_{S}$ (given by Eq. 17) and consequently the capacity of the particle to evacuate the absorbed energy according to Eq. 16.

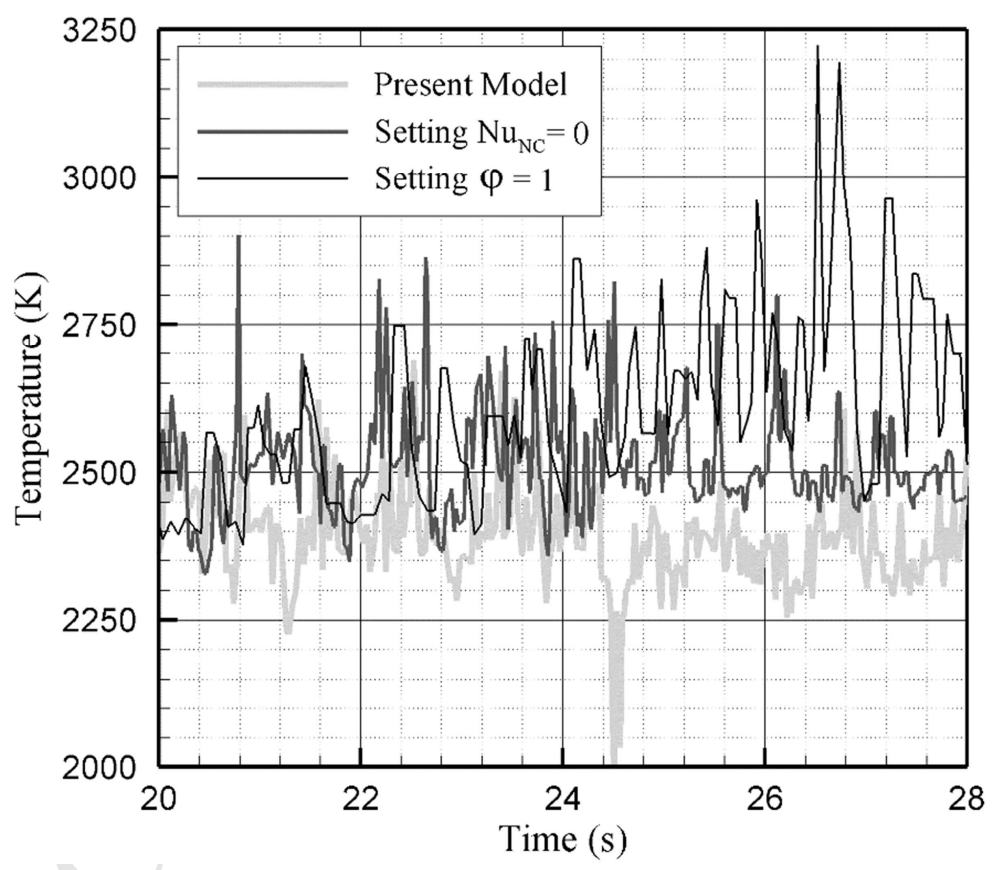

Fig. 8. Time-evolution of the maximum fuelbed temperature in experiment EXMC23 of Catchpole et al. [12] (see Tab. 2 for details) obtained (i) using the present improved model, (ii) by setting $N u_{N C}=0$ in Eq. 18, and (iii) by setting $\varphi=1$ in Eqs. 4 and 9.

A simpler and more accurate method for estimating the ROS consists in finding at each time step of simulation the average position of the pyrolysis front at the fuelbed surface. This was done by determining the average position of the most remote points at the fuelbed surface and downstream the burner that are characterized by zero dry fuel (wood) mass fraction. In Fig. 3-b, we clearly distinguish the pyrolysis front, it corresponds to the 
interface located at about $x=7.6 \mathrm{~m}$. Figure 9 shows the time evolution of the pyrolysisfront positions for duly chosen simulations. We notice, as expected, that increasing the wind speed $U$ or decreasing the solid-fuel moisture-content $M$ or volume-fraction $\alpha_{S}$ increases the rate of fire spread. However, the fuelbed depth has no significant influence on the ROS, in agreement with experimental observations [12]. We can also notice that for two tests (EXMC 82 and MF37), the dry fuel located above the burner did not fully burn at the end of the ignition phase (which occurs between time equal $5 \mathrm{~s}$ and $10 \mathrm{~s}$ and according to Eq. 62), this explains the time lag in Fig. 9 observed for these two tests. We also notice that in the case of fast fire spreads obtained for a sparse solid-fuel bed $\left(\alpha_{S}=0.005\right)$, the fuelbed length ( $8 \mathrm{~m}$ ) was not long enough enable the fire to reach stabilized propagation conditions (with a constant ROS). Whereas for more dense solid-fuel beds and lower fire rates of spread, for EXMC $82\left(\alpha_{S}=0.015\right)$ and MF $37\left(\alpha_{S}=0.018\right)$, a constant value of the ROS was rapidly reached.

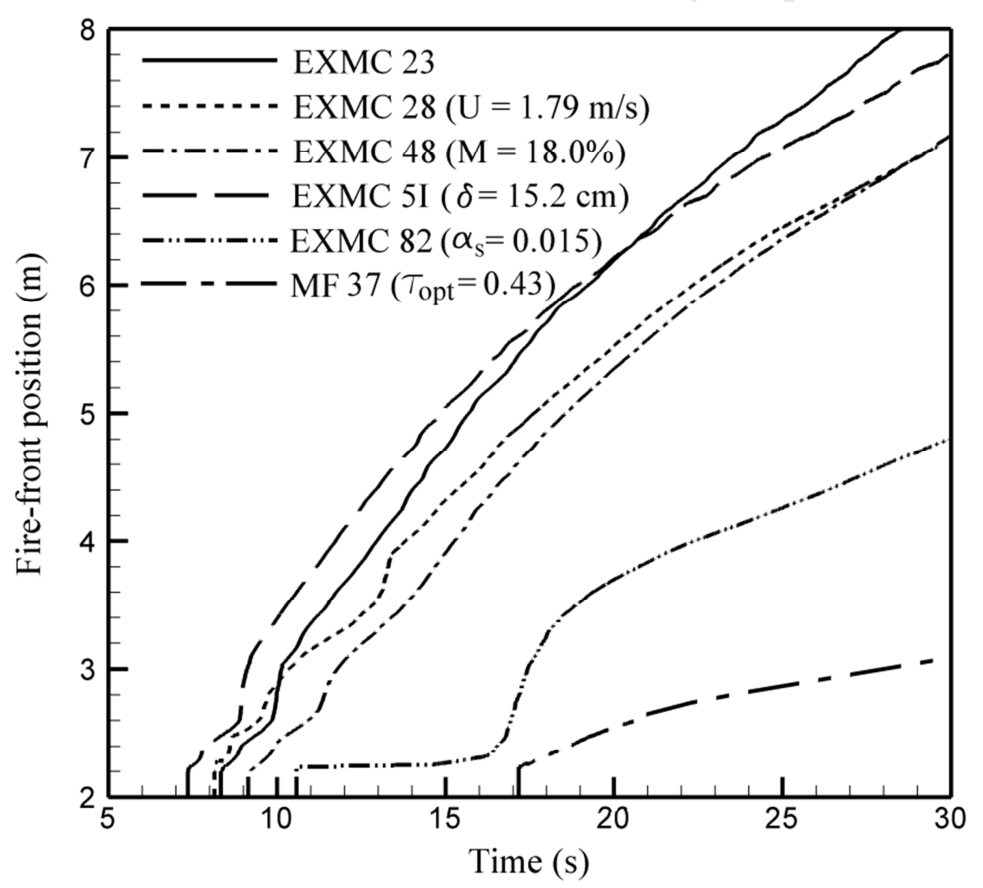

Fig. 9. Time-evolution of the average position of the pyrolysis front at the fuelbed surface for duly chosen simulations. For each experiment, the legend reports the parameter that differs significantly from that of experiment EXMC23, showing the effect of several parameters on the rate of fire spread.

The ROS (average value and standard deviation) was obtained from Fig. 9 by evaluating the slopes of each curve every $0.5 \mathrm{~m}$, omitting the first $1.5 \mathrm{~m}$ (as done experimentally). The fire rates of spread evaluated numerically were compared to the values measured experimentally in Fig. 10 and in Tab. 3. On this kind of graph, a point located on the first diagonal would correspond to perfect numerical prediction of the experimental value. To 
complete the analysis, we have also reported (both in Fig. 10 and in Tab. 3) the values of ROS obtained using the correlation given by Eq. (38) that was established by Catchpole et al. [12] for different fuel types and properties.

$$
R O S=\frac{\left(495.5+1934 U^{0.91}\right) e^{-347 / \sigma_{S}} \alpha_{S}^{-0.499} e^{-0.73 M}}{\rho_{D r y}\left(\Delta h_{P y r}+M \Delta h_{\text {Vap }}\right)}
$$

From values reported in Tab. 3 and in Fig. 10, we can notice that despite the very nonlinear character of this problem, "FireStar3D" predicts correctly the order of magnitude of the ROS. The general trends observed experimentally between the ROS versus the wind speed and versus the solid-fuel parameters are correctly reproduced. We notice however that FireStrar3D seems to globally overestimate the ROS, especially in the case of sparse solid-fuel bed (EXMC24, EXMC28, EXMC36, EXMC48, and EXMC69), for which the predicted values of the ROS (average and standard deviation) were relatively high, reflecting a very unsteady fire propagation.

\begin{tabular}{llccc}
\hline & & Exp. & Simulation & Eq. (38) \\
\hline 1 & EXMC23 & 0.252 & $0.258 \pm 0.094$ & 0.221 \\
2 & EXMC24 & 0.105 & $0.180 \pm 0.033$ & 0.095 \\
3 & EXMC28 & 0.129 & $0.200 \pm 0.063$ & 0.159 \\
4 & EXMC36 & 0.156 & $0.248 \pm 0.077$ & 0.203 \\
5 & EXMC48 & 0.175 & $0.211 \pm 0.080$ & 0.181 \\
6 & EXMC5I & 0.202 & $0.221 \pm 0.065$ & 0.225 \\
7 & EXMC69 & 0.242 & $0.288 \pm 0.083$ & 0.242 \\
8 & EXMC82 & 0.094 & $0.088 \pm 0.017$ & 0.093 \\
9 & EXSC64 & 0.081 & $0.066 \pm 0.004$ & 0.087 \\
10 & EXSC65 & 0.133 & $0.131 \pm 0.005$ & 0.125 \\
11 & EXSC73 & 0.070 & $0.071 \pm 0.011$ & 0.091 \\
12 & EXSC7D & 0.052 & $0.043 \pm 0.003$ & 0.066 \\
13 & MF37 & 0.023 & $0.035 \pm 0.009$ & 0.028 \\
14 & MF38 & 0.052 & $0.065 \pm 0.020$ & 0.067 \\
15 & MF54 & 0.057 & $0.057 \pm 0.002$ & 0.094 \\
\hline
\end{tabular}

Tab. 3. Comparison of the ROS (in $\mathrm{m} / \mathrm{s}$ ) obtained numerically using FireStar3D, experimentally, and using the correlation established in Catchpole et al. given by Eq. (38) for the different experiments shown in Tab. 2. 


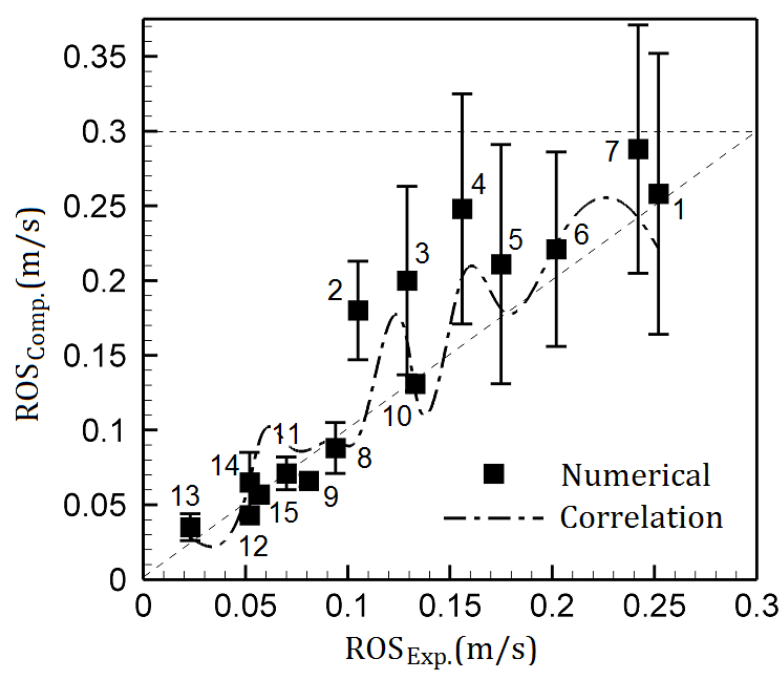

Fig. 10. Comparison between the 15 ROS values (from Tab. 3) obtained experimentally, numerically (with variation interval bars), and from Eq. (38) connected by cubic spline. Experiment numbers are shown in Tab. 2 and in Tab. 3.

841

842

843

844

845

846

847

848

849

850

851

852

853

854

855

856

857

858

859

860

861

862

863

864

865

The more-or-less unsteady character of fire propagation can be illustrated by comparing Figs. 2 and 11 obtained for experiments EXMC23 and MF38, respectively. From these two figures, it is evident that the behavior of the fire was much more unsteady in the case of a relatively sparse solid-fuel bed (Fig. 2) than for a more than 3 times dense solid-fuel bed (Fig. 11), with a corresponding increase of the standard deviation of the ROS as shown in Fig. 10. This can be due to an overestimation of the radiative heat transfer from the walls of the wind tunnel that are assumed to behave as insulated black surfaces (no heat loss by radiation), which is surely not the case in Catchpole et al. experiments [12]. We cannot also exclude that, for rapid fires, the dimensions of the wind tunnel can affect very significantly some aspects of the fire dynamics that were more difficult to reproduce numerically. Paradoxically, even if the experimental conditions are well known at small scale in a laboratory, confined fires (especially for a very low fuel moisture content) can be more difficult to simulate numerically, because of the confinement effect resulting from the interactions between the fire and the walls of the wind-tunnel.

Consequently, the best results were obtained for relatively dense solid-fuel beds (the EXSC and MF series) with a solid-fuel volume fraction ranged between 0.009 and 0.018 , compared to 0.005 for the other cases. It is also for these cases that the lowest values for the ROS (average and standard deviation) were obtained. Because a low value of the ROS means also a less intense fire (and consequently a smaller flame length), we can probably conclude that these differences of behavior observed between the considered set of numerical experiments could be imputed to the confinement effect induced by the walls of the wind-tunnel, which was less important in the case of most tests of the EXSC and MF series than in the case of EXMC series. 
(a)

$\begin{array}{lllllllllllllll}353 & 385 & 450 & 493 & 589 & 685 & 782 & 878 & 1071 & 1186 & 1360 & 1456 & 1553 & 1649 & 1745\end{array}$
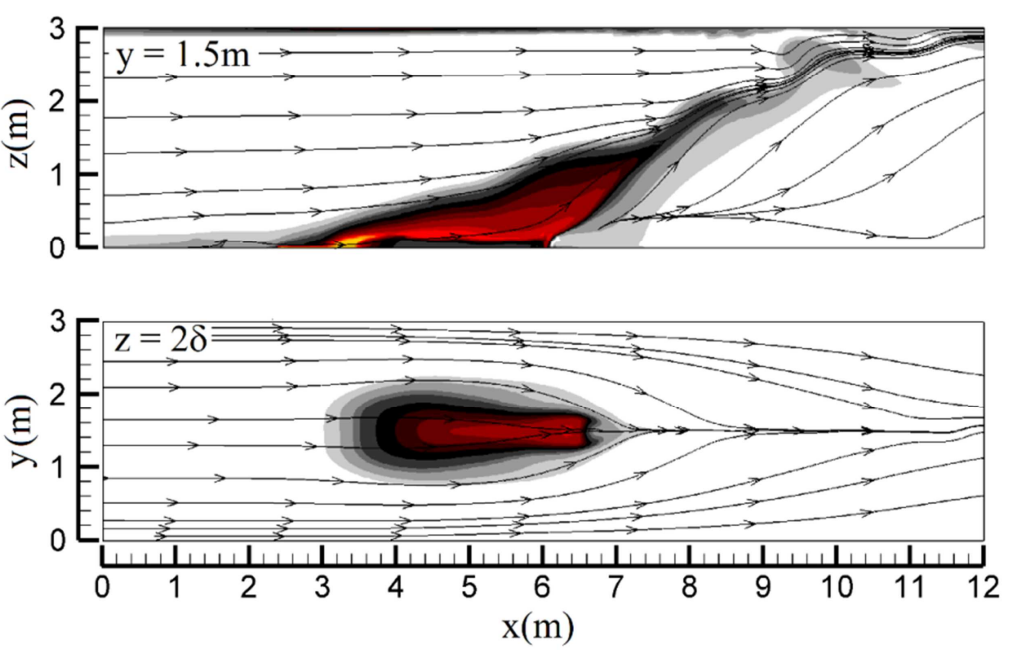

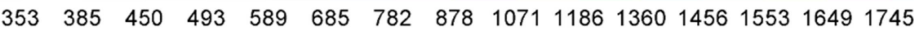

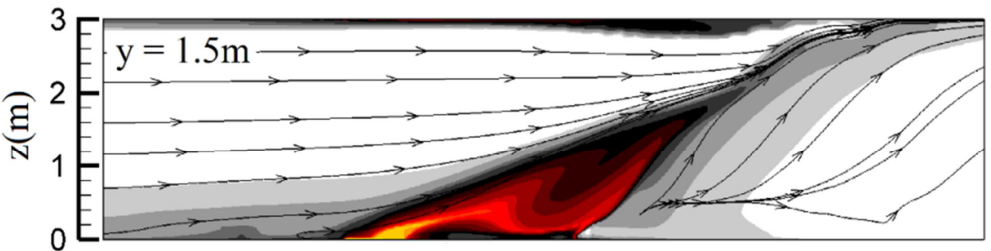

(b)

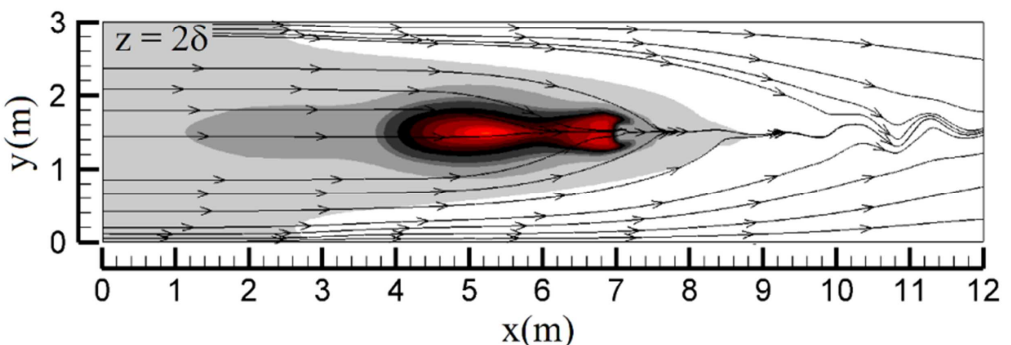

Fig. 11. Temperature fields and streamlines obtained numerically at $t=45 \mathrm{~s}$ (a) and at $\mathrm{t}=60 \mathrm{~s}$ (b) in the case of experiment MF38 of Catchpole et al. [12] (heartwood sticks, wind speed of $U=2.68 \mathrm{~m} / \mathrm{s}$, moisture content $M=6.2 \%$, see Tab. 2 for more details). Top: solution in the vertical median plane ( $\mathrm{y}=1.5 \mathrm{~m})$, bottom: solution in the horizontal plane at $\mathrm{z}=2 \delta$.

To separately evaluate the dependence of the ROS on the fuel moisture content $M$, we have extracted four cases (EXMC23, EXMC36, EXMC48, EXMC69) for which all the simulation parameters were the same $\left(\alpha_{S}=0.005, U=2.68 \mathrm{~m} / \mathrm{s}\right.$, and $\left.\delta=0.203 \mathrm{~m}\right)$, excepted the fuel moisture content $M$ that varied between 3\% and 18.1\%. These results are shown in Fig. 12 that clearly highlights the exponential decay of the ROS with the fuel moisture content; for comparison, an exponential curve $0.3 \times \mathrm{e}^{-0.022} M$ (with $M$ expressed in \%) was represented on 
880

881

882

the same Figure. This exponential decaying has been reported for the experimental data [12] but with an exponent equal to -0.0073 (nearly 3 times smaller than the value predicted by FireStar3D). We should note that the authors in [12] have indicated that this value also exhibited a standard error equal to 0.0035 . In addition, it was not possible to obtained for these four cases a stabilized value of the rate of spread (the test bench being too short), which must be improve in the future.

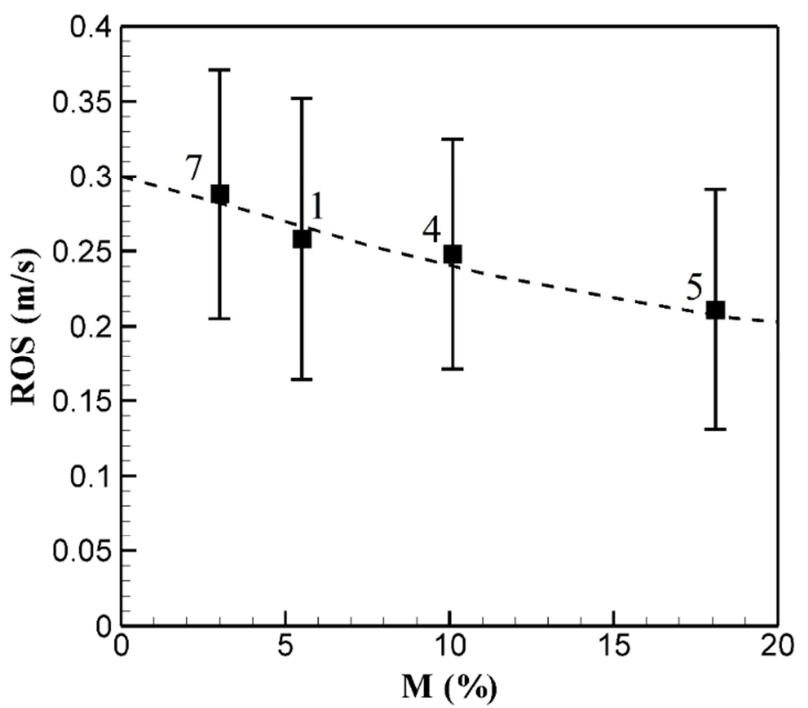

Fig. 12. Evolution of the rate of spread (ROS) as a function of the fuel moisture content (M) for fires propagating through regular excelsior. Experiment numbers are shown in Tab. 2 and in Tab. 3.

This discrepancy in the exponent value between the simulations and the experiments could be explained by the fact that water loss from the vegetation was treated in the model as a simple evaporation process (a phase change at a fixed temperature) while the reality is more complex. The vegetation loses its water through a mechanism of evapotranspiration that starts at a temperature below $100^{\circ} \mathrm{C}$. The characteristic time of an evapotranspiration process is longer than that of a pure evaporation process, and therefore it is not surprising than the impact of the fuel moisture content upon the rate of spread was more important in the model than in the reality.

\section{Conclusions}

A 3D physical model initially developed to predict wildfire behavior and referred to as FireStar3D has been described in this paper. The model consists of solving the conservation equations of the coupled system composed of the vegetation and the surrounding atmosphere, and takes into account the various physical phenomena encountered in a wildfire. Compared to other fire models, FireStar3D is based on a low Mach number 
formulation and solves the transport and the reactive steps in the gaseous phase, which is not the case for HIGRAD/FIRETEC [16]. The radiative heat transfer is fully predicted from the resolution of the radiative transfer equation, which is not always the case in WFDS where a filter is also applied with a presumed radiative fraction in some cases [17]. From a numerical point of view, FireStar3D is based on an implicit solver, as it is the case in the new generation of fire solvers such as FireFOAM [55,56]. A study was carried out in this paper to evaluate the potential of FireStar3D to predict fire behavior in an environmentally-controlled wind tunnel. This constitutes an important step toward the validation of any physical model, in order to reach the final objective of numerically simulating wildfire behavior at large scales. The results have shown that FireStar3D predicted relatively well the correct order of magnitude of the ROS and the correct trends induced by a variation of the wind speed and of the fuelbed characteristics (moisture content and volume fraction), although it seems to overestimate the ROS, especially at low packing ratios. The next step (work in progress) will be the numerical simulations of surface fires in grasslands in similar conditions to those of the experiments carried in Australia and in US [13-14]. With the new generation of outdoor experimental fires [14], additional data can be compared, such as vertical velocity profiles and the time history of the temperature and the turbulent kinetic energy monitored at different heights from the ground. This new step will constitute a great progress in the validation process, because the comparison will incorporate local data and not only integral ones such as the ROS and the intensity of fire. Due to the complexity of the physical phenomena, we are conscious that performing a real time forecast of a wildfire at a very large scale using this kind of model might never be achieved. But this is not our objective; we consider however that this class of physical model is well adapted to study the problem of the interaction between a fire front and a building located at a wildland-urban interface. Other problems could be studied with this kind of model such as the transition between plume-dominated and wind driven fires (which constitutes the two major regimes of propagation of wildfires), the impact of surface fire on soils, the interaction between two fire fronts, the behavior of fires in extreme conditions (very dry fuel, strong wind, very high temperature conditions) which could occur more frequently in the context of global warming, and many other questions in connection with the understanding and the prevention of this natural hazard.

\section{Acknowledgments}

This work was granted access to the HPC resources of Aix-Marseille University financed by the project Equip@Meso (ANR-10-EQPX-29-01) of the program "Investissements d'Avenir" supervised by the "Agence Nationale pour la Recherche".

\section{References}

[1] W.T. Sommers, S.G. Coloff, S.G. Conard, Synthesis of Knowledge: Fire History and Climate Change, JFSP Synth. Reports. Pap. 19. (2011). 
[2] R.J. Whelan, The ecology of fire, 1st Ed., 1995.

[3] J.D. Cohen, The wildland-urban interface fire problem, Fremontia. 38 (2010) 16-22.

[4] W.E. Mell, S.L. Manzello, A. Maranghides, D. Butry, R.G. Rehm, The wildland-urban interface fire problem - current approaches and research needs, Int. J. of Wildland Fire. 19 (2010) 238-251.

[5] H.P. Hanson, M.M. Bradley, J.E. Bossert, R.R. Linn, L.W. Younker, The potential and promise of physics-based wildfire simulation, Environ. Sci. Policy. 3 (2000) 161-172.

[6] M.A. Finney, K.C. Ryan, Use of the FARSITE Fire Growth Model for Fire Prediction in U.S. National Parks, in: Int. Emerg. Manag. Eng. Conf., 1995: p. 186.

[7] A.M. Grishin, Mathematical modeling of forest fires and new methods of fighting them., in: F. Albini (Ed.), Tomsk Univ., 1997.

[8] D. Morvan, J.L. Dupuy, Modeling the propagation of a wildfire through a Mediterranean shrub using a multiphase formulation, Combust. Flame. 138 (2004) 199-210.

[9] D. Morvan, S. Meradji, G. Accary, Wildfire Behavior Study in a Mediterranean Pine Stand Using a Physically Based Model, Combust. Sci. Technol. 180 (2008) 1-19.

[10] D. Morvan, S. Meradji, G. Accary, Physical modeling of fire spread in Grasslands, Fire Safety Journal 44 (2008) 50-61.

[11] R.R. Linn, J.M. Canfield, P. Cunningham, C. Edminster, J.L. Dupuy, F. Pimont, Using periodic line fires to gain a new perspective on multi-dimensional aspects of forward fire spread, Agric. For. Meteorol. 157 (2012) 60-76.

[12] W.R. Catchpole, E.A. Catchpole, B.W. Butler, R.C. Rothermel, G.A. Morris, D.J. Latham, Rate of Spread of Free-Burning Fires in Woody Fuels in a Wind Tunnel, Combust. Sci. Technol. 131 (1998) 1-37.

[13] N.P. Cheney, J.S. Gould, W.R. Catchpole, Prediction of fire spread in grasslands, Int. J. of Wildland Fire. 8 (1998) 1-13.

[14] C.B. Clements, S. Zhong, S. Goodrick, J. Li, B.E. Potter, X. Bian, W.E. Heilman, J.J. Charney, R. Perna, M. Jang, D. Lee, M. Patel, S. Street, G. Aumann, Observing the dynamics of wildland grass fires: FireFlux - A field validation experiment, Bull. Am. Meteorol. Soc. 88 (2007) 1369-1382.

[15] D. Morvan, Physical phenomena and length scales governing the behavior of wildfires: a case for physical modelling, Fire Technology, 47 (2011), 437-460.

[16] R.R. Linn, P. Cunningham, Numerical simulations of grass fires using a coupled atmosphere -fire model: Basic fire behavior and dependence on wind speed, J. Geophys. Res. 110 (2005) D13107.

[17] K.W. Mell, A. Maranghides, R. McDermott, S.L. Manzello, Numerical simulation and experiments of burning douglas fir trees, Combust. Flame. 156 (2009) 2023-2041.

[18] Y. Horibata, Numerical simulation of a low-Mach-number flow with a large temperature variation, Computers and Fluids 21(2) (1992) 185-200. 
[19] N.D. Burrows, Flame residence times and rates of weight loss of eucalypt forest fuel particles, Int. J. of Wildland Fire. 10 (2001) 137-143.

[20] Cheney NP (1981) In: Gill RH, Groves RH, Noble IR (eds) Fire and the Australian biota. Autralian Academy of Science, Canberra, p 151

[21] C. Di Blasi, C. Branca, A. Santoro, E. Gonzalez Hernandez, Pyrolytic behavior and products of some wood varieties, Combust. Flame. 124 (2001) 165-177.

[22] P. Mindykowski, A. Fuentes, J.L. Consalvi, B. Porterie, Piloted ignition of wildland fuels, Fire Safety Journal 46 (2011) 34-40.

[23] D.D. Evans, H.W. Emmons, Combustion of wood charcoal, Fire Research 1 (1977) 5766.

[24] A.P. Dimitrakopoulos, Thermogravimetric analysis of Mediterranean plant species, J. Anal. Appl. Pyrolysis. 60 (2001) 123-130.

[25] C. Moro, Technical Report PIF9702, INRA, Equipe Prévention Des Incend. Forêt. (1997).

[26] F.P. Incropera, D.P. DeWitt, Fundamentals of Heat and Mass Transfer, John Wiley and Sons, 1996.

[27] A. Favre, L.S.G. Kovasznay, R. Dumas, J. Gaviglio, M. Coantic, La turbulence en mécanique des fluides, Gauthier-Villars. (1976).

[28] S. Paolucci, On the filtering of sound from the Navier Stokes equations, (1982) SAND82-8257.

[29] R.J. Kee, F.M. Rupley, J.A. Miller, The CHEMKIN Thermodynamic Data Base, Sandia Natl. Lab. (1990).

[30] C.R. Kaplan, C.R. Shaddix, K.C. Smyth, Computations of enhanced soot production in time-varying CH4/air diffusion flames, Combust. Flame. 106 (1996) 392-405.

[31] G. Cox, Combustion fundamentals of fire, Acad. Press. (1995).

[32] S.A. Orszag, I. Staroselsky, W.S. Flannery, Y. Zhang, Introduction to renormalization group modeling of turbulence, Simul. Model. Turbul. Flows. (1996) 155-183.

[33] G.G. Katul, L. Mahrt, D. Poggi, Ch. Sanz, One and two equation models for canopy turbulence, Boundary-Layer Meteorology, 113 (2004) 81-109.

[34] B.F. Magnussen, B.H. Hjertager, On mathematical modeling of turbulent diffusion flame in cross flow, Combust. Sci. Technol. 140 (1998) 93-122.

[35] Z.Q. Li, F. Wei, Y. Jin, Numerical simulation of pulverized coal combustion and NO formation, Chem. Eng. Sci. 58 (2003) 5161-5171.

[36] K.J. Syed, C.D. Stewart, J.B. Moss, Modelling soot formation and thermal radiation in buoyant turbulent diffusion flames, Combust. Inst. 23 (1991) 1533-1541.

[37] J.B. Moss, G. Cox, Turbulent Diffusion Flame, Acad. Press. London, UK. 21 (1990) 221272. 
[38] J. Nagle, R.F. Strickland-Constable, Oxidation of Carbon Between 1000-2000 C, Proc. Fifth Carbon Conf. 1 (1962) 154-164.

[39] C.R. Kaplan, S.W. Baek, E.S. Oran, J.L. Ellzey, Dynamics of a strongly radiating unsteady ethylene jet diffusion flame, Combust. Flame, 96 (1994) 1-21.

[40] H.K. Versteeg, M. Malalasekera, An Introduction to Computational Fluid Dynamics. The Finite Volume Method, 2nd Editiont, 2007.

[41] D. Morvan, M. Larini, Modeling of one dimensional fire spread in pine needles with opposing air flow, Combust. Sci. Technol. 164 (2001) 37-64.

[42] D. Morvan, Physical phenomena and length scales governing the behaviour of wildfires, Fire Technology, 47 (2011) 437-460.

[43] P.M. Gresho, R.L. Lee, R.C. Sani, On the time-dependent solution of the incompressible Navier-Stokes equations in two and three dimensions, Recent Adv. Numer. Methods Fluids, Vol. 1.1 (1979) 27-79.

[44] B.P. Leonard, A stable and accurate convective modeling procedure based on quadratic interpolation., Comput. Methods Appl. Mech. Eng. 19 (1979) 59-98.

[45] D.S. Jang, R. Jetli, S. Acharya, Comparison of the Piso , Simpler , and Simplec Algorithms for the Treatment of the Pressure- Velocity Coupling in Steady Flow Problems, Numer. Heat Transf. An Int. J. Comput. Methodol. 10 (1986) 209-228.

[46] R. Barrett, M. Berry, T.F. Chan, J. Demmel, J.M. Donato, J. Dongarra, V. Eijkhout, R. Pozo, C. Romine, H. Van der Vorst, Templates for the Solution of Linear Systems: Building Blocks for Iterative Methods, 2nd Edition, Siam. (1994).

[47] G. Accary, O. Bessonov, D. Fougère, K. Gavrilov, S. Meradji, D. Morvan, Efficient parallelization of the preconditioned conjugate gradient method, Lect. Notes Comput. Sci. (Including Subser. Lect. Notes Artif. Intell. Lect. Notes Bioinformatics). 5698 LNCS (2009) 60-72.

[48] A.J. Chorin, A numerical method for solving the incompressible and low speed compressible equations, J. Comput. Phys. 137 (1997) 118-125.

[49] M.F. Modest, Radiative heat transfer, 2003.

[50] G. Accary, O. Bessonov, D. Fougère, S. Meradji, D. Morvan, Optimized Parallel Approach for 3D Modelling of Forest Fire Behaviour, V.E. Malyshkin (Ed.), PaCT 2007, LNCS, Springer, Heidelb. 4671 (2007) 96-102.

[51] G. Accary, S. Meradji, D. Morvan, D. Fougère, Towards a numerical benchmark for 3D mixed-convection low Mach number flows in a rectangular channel heated from below, Fluid Dyn. Mater. Process. 141 (2008) 1-7.

[52] J.L. Dupuy, R.R. Linn, V. Konovalov, F. Pimont, J.A. Vega, E. Jiménez, Exploring threedimensional coupled fire-atmosphere interactions downwind of wind-driven surface fires and their influence on backfires using the HIGRAD-FIRETEC model, Int. J. of Wildland Fire. 20(6) (2011) 734-750.

[53] D. Morvan, S. Méradji, W. Mell, Interaction between head fire and backfire in 
1051

1052

1053

1054

1055

1056

1057

1058

grasslands, Fire Safety Journal. 58 (2013) 195-203.

[54] J.L. Dupuy, J. Maréchal, D. Morvan, Fires from a cylindrical forest fuel burner: combustion dynamics and flame properties. Combust. Flame, 135 (2003) 65-76.

[55] Y. Wang, P. Chatterjee, J.L. de Ris, Large Eddy Simulation of Fire Spread, Proc. Combust. Inst. 33 (2011) 2473-2480.

[56] M. El Houssami, J.C. Thomas, A. Lamorlette, D. Morvan, M. Chaos, R. Hadden. Experimental and numerical studies characterizing the burning dynamics of wildland fuels, Combust. Flame, 168 (2016) 113-126. 
- Numerical simulations of surface fire through an homogeneous fuel bed

- Detailed physical fire model

- Comparison with the experiments carried out in the wind-tunnel of the Missoula Fire Sciences Lab 